ARTICLE

\title{
Cell cycle and p53 gate the direct conversion of human fibroblasts to dopaminergic neurons
}

Houbo Jiang 1,2, Zhimin $X u^{2,3}$, Ping Zhong ${ }^{1,2}$, Yong Ren², Gaoyang Liang ${ }^{4}$, Haley A. Schilling ${ }^{2}$, Zihua Hu ${ }^{5}$, Yi Zhang ${ }^{4}$, Xiaomin Wang ${ }^{6}$, Shengdi Chen ${ }^{3}$, Zhen Yan $^{1,2}$ \& Jian Feng ${ }^{1,2,6}$

The direct conversion of fibroblasts to induced dopaminergic (iDA) neurons and other cell types demonstrates the plasticity of cell fate. The low efficiency of these relatively fast conversions suggests that kinetic barriers exist to safeguard cell-type identity. Here we show that suppression of p53, in conjunction with cell cycle arrest at G1 and appropriate extracellular environment, markedly increase the efficiency in the transdifferentiation of human fibroblasts to iDA neurons by Ascl1, Nurr1, Lmx1a and miR124. The conversion is dependent on Tet1, as G1 arrest, p53 knockdown or expression of the reprogramming factors induces Tet1 synergistically. Tet1 knockdown abolishes the transdifferentiation while its overexpression enhances the conversion. The iDA neurons express markers for midbrain DA neurons and have active dopaminergic transmission. Our results suggest that overcoming these kinetic barriers may enable highly efficient epigenetic reprogramming in general and will generate patient-specific midbrain DA neurons for Parkinson's disease research and therapy.

\footnotetext{
${ }^{1}$ Veterans Affairs Western New York Healthcare System, Buffalo, New York 14215, USA. ${ }^{2}$ Department of Physiology and Biophysics, State University of New York at Buffalo, Buffalo, New York 14214, USA. ${ }^{3}$ Department of Neurology and Institute of Neurology, Ruijin Hospital Affiliated to Shanghai Jiao Tong University School of Medicine, Shanghai 200025, China. ${ }^{4}$ Howard Hughes Medical Institute, Departments of Genetics \& Pediatrics, Harvard Medical School, Boston, Massachusetts 02115, USA. ${ }^{5}$ Center for Computational Research, New York State Center of Excellence in Bioinformatics \& Life Sciences, State University of New York at Buffalo, Buffalo, New York 14260, USA. ${ }^{6}$ Department of Neurobiology, Key Laboratory for Neurodegenerative Disorders of the Ministry of Education, Beijing Institute for Brain Disorders, Capital Medical University, Beijing 100069, China. Correspondence and requests for materials should be addressed to J.F. (email: jianfeng@buffalo.edu).
} 
$\mathrm{n}$ a multicellular organism, different types of cells are generated in a deterministic manner during development from a single totipotent cell. This unidirectional process and the stability of cell-type identity suggest that a self-reinforcing mechanism is at work to maintain distinct cell-type identities, all of which are expressed from the same genome. A few earlier studies, for example, on $\mathrm{MyoD}^{1}$, have shown that cell-type identity can be radically changed by a single transcription factor, which rewires the transcription network in such a way that the same genome can express a different cell type. It has now been established that virtually any type of cell can be reprogrammed to induced pluripotent stem (iPS) cells by defined factors ${ }^{2}$ in a multistaged, stochastic process that requires many rounds of cell divisions ${ }^{3}$. Ablation of the p53 pathway greatly enhances the efficiency in the derivation of iPS cells ${ }^{4-9}$, although the underlying mechanism remains unclear. The plasticity of cell-type identity is further demonstrated by the direct conversion of fibroblasts to induced dopaminergic (iDA) neurons ${ }^{10-12}$ and other cell types ${ }^{13-16}$. Ascl 1 is a critical transcription factor in the transdifferentiation of fibroblasts to induced neurons ${ }^{17}$. It converts embryonic carcinoma cells to neurons and causes rapid cell cycle exit, presumably by inducing the cyclin-dependent kinase inhibitor p27 ${ }^{\mathrm{Kipl}}$ (ref. 18). Cellular reprogramming from one epigenetic state to another requires changes in epigenetic modifiers. Tet proteins are a family of three DNA hydroxylases that critically regulate the epigenome through the oxidation of 5-methylcytosine $(5 \mathrm{mC})$ to 5-hydroxymethylcytosine $(5 \mathrm{hmC})$ and other products ${ }^{19}$. The very high levels of $5 \mathrm{hmC}$ in neurons ${ }^{20}$ and the critical role of Tet proteins in epigenetic reprogramming, such as the derivation of iPSCs ${ }^{21}$, suggest that they may play important roles in epigenetic conversion of fibroblasts to neurons.

The direct conversion of fibroblasts to many types of cells, including iDA neurons, is a relatively fast process that manifests itself within days ${ }^{10-12}$. However, the low efficiency of the conversion suggests that conditions additional to the requisite transcription factors must be met to enable highly efficient cellular reprogramming. Identification of kinetic barriers to transdifferentiation would reveal significant mechanistic insight into cellular reprogramming in general and produce highly efficient ways to generate many types of useful cells from readily available sources such as fibroblasts. In this study, we show that attenuation of $\mathrm{p} 53$, in conjunction with cell cycle arrest at G1 and appropriate cell culture environment, increases the efficiency in the transdifferentiation of human fibroblasts to iDA neurons. The epigenetic conversion is dependent on Tet1, as p53 knockdown, G1 arrest and induction of reprogramming factors synergistically induce Tet1. Furthermore, Tet1 knockdown abolishes the conversion while its overexpression enhances the transdifferentiation. The iDA neurons express markers for midbrain DA neurons and exhibit active dopaminergic transmission.

\section{Results}

Attenuation of p53 increases the derivation of iDA neurons. Human fetal lung fibroblast MRC5 (Medical Research Council 5) cells, which are widely used in many reprogramming experiments ${ }^{22}$, were infected with tetracycline-inducible lentiviruses expressing human Ascl1, Nurr1 and Lmxla (ANL) ${ }^{10}$, miRNA124 (refs 23,24) and a constitutively active lentivirus for $\mathrm{p} 53$ shRNA. They were cultured in neural induction media ${ }^{25}$ with the protocol in Fig. 1a. After 3 days of induction with doxycycline (Dox, $1 \mu \mathrm{g} \mathrm{ml}^{-1}$ ), some cells exhibited a compact cell body with one or many long processes, reminiscent of neurons. When the cells were stained at day 9 with antibodies against tyrosine hydroxylase (TH), a marker for dopaminergic (DA) neurons, and $\beta 3$-tubulin (Tuj1), a neuronal marker, we found that p53 knockdown significantly increased the generation of Tuj1 ${ }^{+}$ cells $(25.4 \pm 1.8 \%$ of all cells $)$ and $\mathrm{TH}^{+}$cells $(8.4 \pm 0.8 \%$ of all cells) over the levels induced by ANL alone $(17.9 \pm 1.2 \%$ for Tuj $1^{+}, 6.3 \pm 0.8$ for $\mathrm{TH}^{+}, P<0.05$, unpaired, two-tailed Student's $t$-tests; Fig. 1b,c,f). miR124 significantly enhanced the efficiency of ANL in generating $\mathrm{TH}^{+}$cells $(8.3 \pm 0.6 \%, P<0.05$, unpaired, two-tailed Student's $t$-tests), but not Tuj1 ${ }^{+}$cells $(18.2 \pm 1.2 \%$; Fig. $1 \mathrm{~d}, \mathrm{f})$. The combination of ANL with miR124 and p53 shRNA (ANLmp) resulted in marked increases in Tuj ${ }^{+}$ cells $(31.1 \pm 1.9 \%, P<0.05$, unpaired, two-tailed Student's $t$-tests) and $\mathrm{TH}^{+}$cells $(15.4 \pm 1.1 \%, P<0.05$, unpaired, two-tailed Student's $t$-tests; Fig. 1e,f). The total number of cells $\left(\mathrm{DAPI}^{+}\right)$ at day 9 was not significantly affected by the different combinations of viruses (Fig. 1g). Thus, the ratio of $\mathrm{TH}^{+}$/ $\mathrm{DAPI}^{+}$or Tuj $1^{+} / \mathrm{DAPI}^{+}$(that is, reprogramming efficiency) is consistent with the total number of $\mathrm{TH}^{+}$or Tuj $1^{+}$cells (that is, reprogramming yield; Fig. 1g). p53 knockdown did not significantly change the total number of cells at day 9 , as the initial overgrowth of mitotic cells led to more cell death after the reprogramming factors were turned on by DOX. Western blotting of p53 at day 1 confirmed its reduced expression by the p53 shRNA lentivirus, while miR124 did not have a significant effect on p53 level (Fig. 1h). Using NIH ImageJ with NeuronJ plugin ${ }^{26}$, we traced the neurites and analysed total neurite length and the number of neurites for $\mathrm{TH}^{+}$cells derived from different conditions. p53 shRNA or miR124 significantly increased total neurite length (Fig. 1i) and the number of neurites (Fig. 1j), when compared with the situation with ANL alone. ANLmp produced even greater increases in total neurite length (Fig. 1i) and the number of neurites (Fig. 1j).

To substantiate the effect of p53 knockdown, we manipulated p53 levels using nutlin-3a, which inhibits MDM2-mediated degradation of p53 (ref. 27), or overexpression of MDM2 (ref. 28). Indeed, nutlin-3a increased p53 level and significantly decreased reprogramming efficiency (Fig. 1k). Conversely, overexpression of MDM2 reduced p53 level and significantly increased reprogramming efficiency (Fig. 11). We performed array comparative genomic hybridization to compare genomic DNA from MRC5 fibroblasts and MRC5-derived induced neurons. There was no significant genomic change (Supplementary Fig. 1), which is consistent with the very low expression level of the p53 shRNA transgene (Supplementary Fig. 2). All the other four transgenes (ANLm) were greatly silenced in induced neurons (Supplementary Fig. 2).

The effect of p53 knockdown is not affected by p21. p53 induces $\mathrm{p} 21$, which binds to and inhibits cyclin-dependent kinases (CDKs), preventing the phosphorylation of critical CDK substrates and thus blocking cell cycle progression ${ }^{29}$. Consequently, p53 knockdown promotes cell proliferation in mitotic cells. To investigate whether the enhancing effect of p53 knockdown on the derivation of iDA neurons is connected to the effect of p53 knockdown on cell cycle progression, we tested whether overexpression of $\mathrm{p} 21$, which blocks the proliferative effect of p53 knockdown, affects derivation of iDA neurons. The same number of MRC5 cells $\left(2 \times 10^{4}\right.$ per well $)$ were plated on day -2 and infected on day -1 with lentiviruses expressing ANLmp or ANLmp plus p21 (ANLmp21) according to the protocol in Fig. 1a. Dox was added at day 0 to induce the expression of ANLm, while the expression of p53 and p21 were constitutive. We trypsinized the cells at different days to count the total number of live cells by trypan blue staining. Overexpression of p21 led to significantly fewer cells in comparison to ANLmp 
a
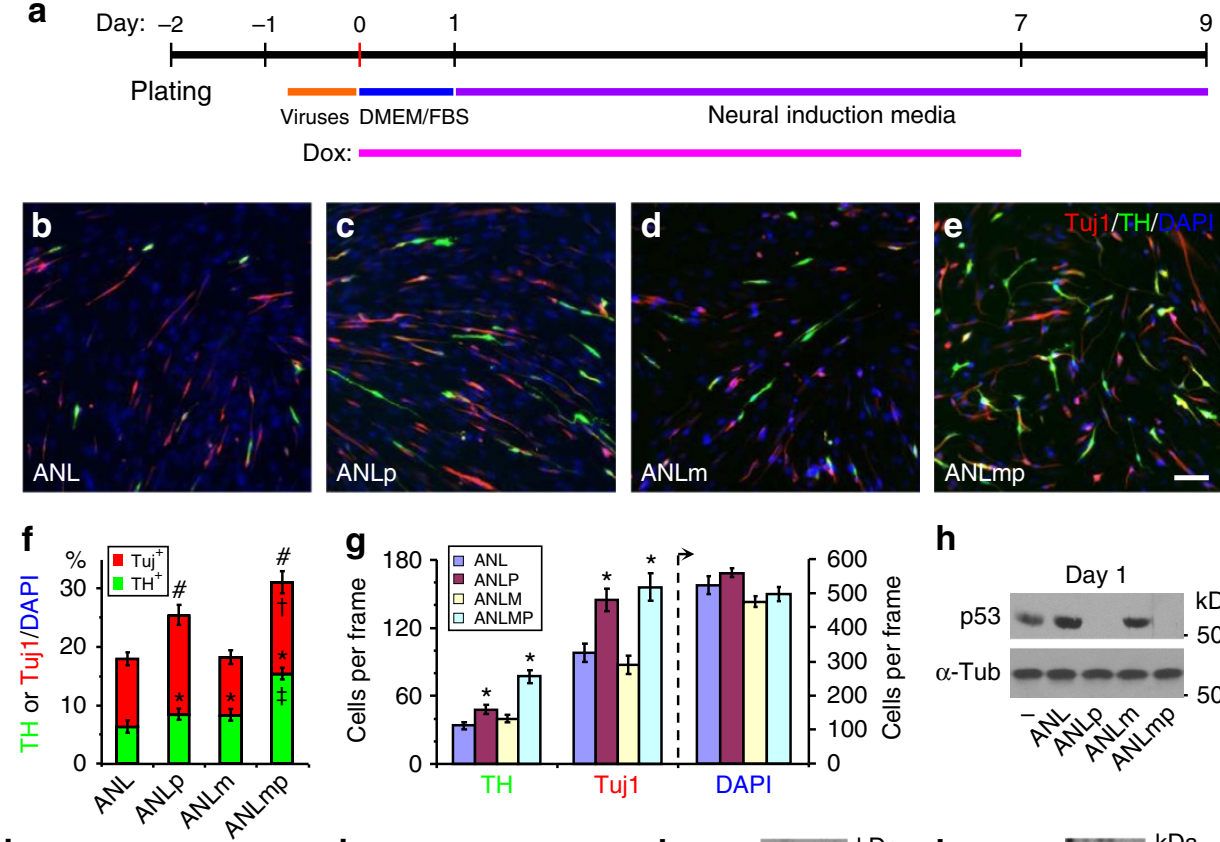

h
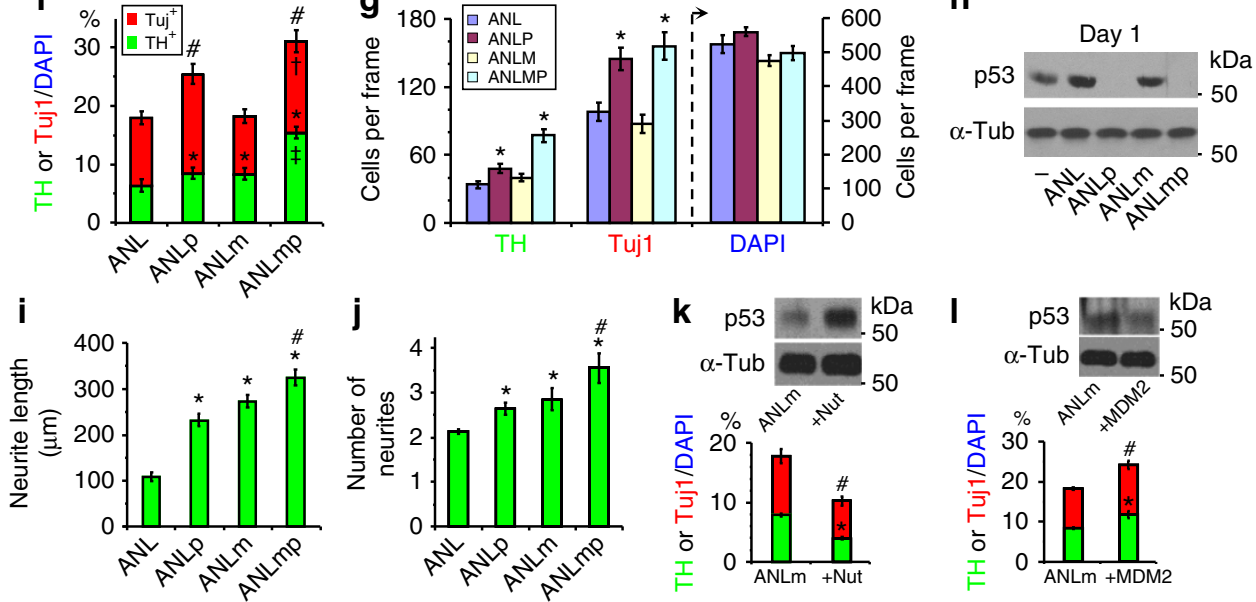

Figure 1 | p53 attenuation enhances the conversion of human fibroblasts to iDA neurons. (a-e) Using the protocol in a, MRC5 cells were reprogrammed to iDA neurons in neural induction media with lentiviruses expressing Ascl1, Nurr1 and Lmxla (ANL) (b), ANL plus p53 shRNA (ANLp) (c), ANL plus miR124 (ANLm) (d) or ANL plus miR124 and p53 shRNA (ANLmp) (e). Scale bar, $100 \mu \mathrm{m}$. (f,g) Percentage of $\mathrm{TH}^{+}$or Tuj $^{+}$cells in all cells $\left(\mathrm{DAPI}^{+}\right.$) at day 9 (f). ${ }^{\star}, \# P<0.05$, unpaired, two-tailed Student's $t$-tests versus $\mathrm{TH}^{+}$or Tuj ${ }^{+}$in ANL, respectively. ${ }^{\ddagger}{ }^{\dagger} P<0.05$, unpaired, two tailed Student's $t$-tests versus $\mathrm{TH}^{+}$or Tuj1 ${ }^{+}$in ANLm, respectively; $n=8$ wells from four independent experiments for each condition. Average numbers of $\mathrm{TH}^{+}, \mathrm{Tuj}^{+}$or $^{+}$ $\mathrm{DAPI}^{+}$cells per frame under $\times 10$ lenses were plotted in $\mathbf{g} .{ }^{\star} P<0.05$, unpaired, two tailed Student's $t$-tests versus $\mathrm{ANL}$ for $\mathrm{TH}^{+}$or Tuj ${ }^{+}$cells, respectively; $n=8$ wells from four independent experiments for each condition. The scale for $\mathrm{DAPI}^{+}$cells is according to the $y$ axis on the right. (h) Western blotting of p53 and $\alpha$-tubulin ( $\alpha$-Tub) in total cell lysates at day 1 . Total neurite length (i) and number of neurites $(\mathbf{j})$ per TH ${ }^{+}$neurons. ${ }^{\star} P<0.05$, unpaired, two tailed Student's $t$-tests versus ANL; ${ }^{\#} P<0.05$, unpaired, two tailed Student's $t$-tests versus $\mathrm{ANLm} n=30-60 \mathrm{TH}^{+}$neurons from three independent experiments for each condition. (k, $\mathbf{I})$ The reprogramming efficiency with ANLm or ANLm plus nutlin-3a (k) or with ANLm plus MDM2 (I). ${ }^{*}{ }^{\#} P<0.05$, unpaired, two tailed Student's $t$-tests versus $\mathrm{TH}^{+}$or Tuj $1^{+}$, respectively; $n=6$ wells from 3 independent experiments for each condition. Insets, western blotting of p53 and $\alpha$-tubulin. Error bars denotes standard error of measurement.

alone ( $P<0.05$, unpaired, two-tailed Student's $t$-tests; Fig. $2 \mathrm{a})$, as cell death was visibly increased. p53 knockdown ablated the expression of p53 and p21. Overexpression of exogenous p21 restored p21 level (Fig. 2b). The double bands for p21 is due to its phosphorylation $^{30}$. Full western blotting images of p53 and p21 are shown in Supplementary Fig. 3. There was no significant difference in the number of $\mathrm{TH}^{+}$or $\mathrm{Tuj} 1^{+}$cells when the cultures were stained at day $9(P>0.05$, unpaired, two-tailed Student's $t$-tests). However, the number of DAPI ${ }^{+}$cells was significantly reduced $(P<0.05$, unpaired, two-tailed Student's $t$ tests, ANLmp21 versus ANLmp; Fig. 2c-e). It seems that p21 overexpression and p53 knockdown caused a conflict only in mitotic cells, which decreased the number of these cells $\left(\mathrm{DAPI}^{+} /\right.$ Tuj1 ${ }^{-}$, Fig. 2e) through reduced proliferation and increased cell death. Thus, the percentage of $\mathrm{TH}^{+}$or Tuj1 ${ }^{+}$cells in $\mathrm{DAPI}^{+}$ cells was increased significantly $(P<0.05$, unpaired, two-tailed Student's $t$-tests, ANLmp21 versus ANLmp; Fig. 2f). The results suggest that the effect of p53 knockdown on the reprogramming of fibroblasts to iDA neurons is independent of the effect of p53 on cell cycle. The two effects are actually opposing, as p53 knockdown increases cell proliferation while the fibroblast-toneuron conversion generates postmitotic neurons. Thus, the conversion efficiencies as measured by $\mathrm{TH}^{+} / \mathrm{DAPI}^{+}$or $\mathrm{Tuj}^{+} / \mathrm{DAPI}^{+}$ratios were increased when $\mathrm{p} 21$ blocked the proliferative effect of p53 knockdown.

G1 arrest facilitates the conversion to iDA neurons. The dual effects of p53 knockdown in enhancing fibroblast-to-neuron conversion and cell proliferation led us to examine how cell cycle affects the transdifferentiation. We found that p53 knockdown (in ANLp or ANLmp) markedly increased the percentage of 5-ethynyl-2'-deoxyuridine-positive $\left(\mathrm{EdU}^{+}\right)$cells (Fig. 3a and Supplementary Fig. 4). In contrast, the induction of ANL (or ANLm) by Dox rapidly and markedly reduced the percentage of $\mathrm{EdU}^{+}$cells, suggesting that the conversion of fibroblasts to neurons is accompanied by rapid cell cycle exit (within $24 \mathrm{~h}$ of Dox induction), as have been reported previously ${ }^{13,18}$. Fibroblasts 
a
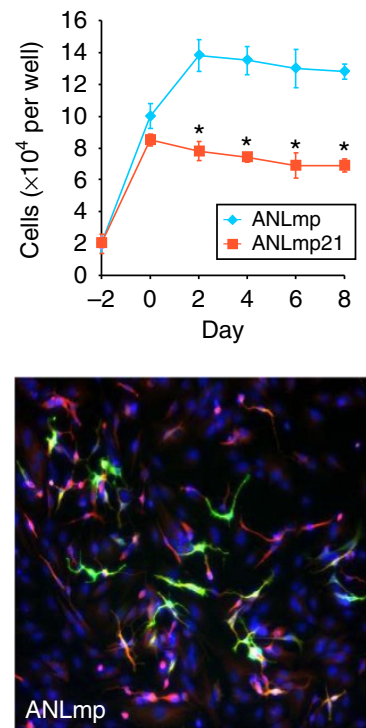

e

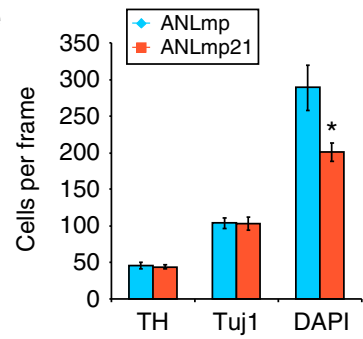

b
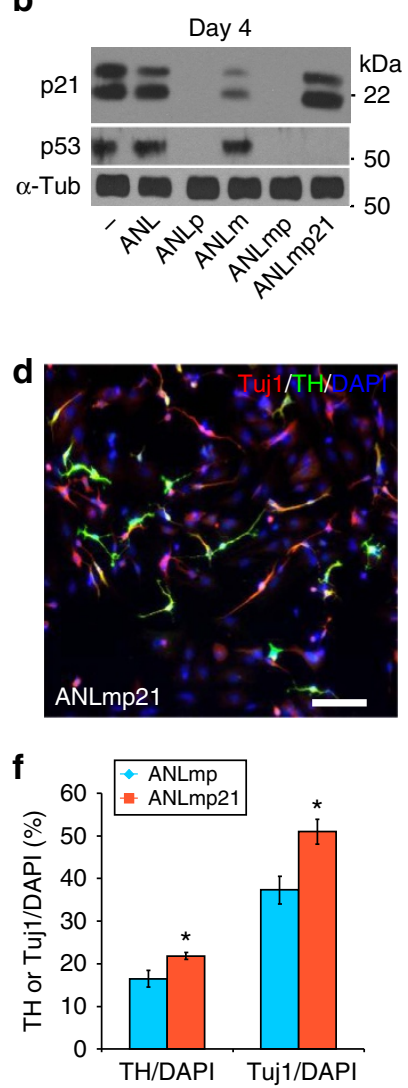

Figure 2 | The effect of p53 knockdown is not affected by p21. (a) The number of live cells by trypan blue staining at different days for MRC5 cells transduced with lentiviruses expressing ANLmp or ANLmp plus p21 (ANLmp21). (b) Western blotting of p21, p53 and $\alpha$-tubulin ( $\alpha$-Tub) in total cell lysates from MRC5 cells transduced with the indicated lentiviruses at day 4. (c,d) Representative images of iDA neurons converted from MRC5 cells transduced with lentiviruses expressing ANLmp (c) or ANLmp21 (d) in neural induction media. Scale bar, $100 \mu \mathrm{m}$. (e,f) Quantification of the number of $\mathrm{TH}^{+}, \mathrm{Tuj}^{+}$or DAPI ${ }^{+}$cells at day $9(\mathbf{e})$, and the ratio of $\mathrm{TH}^{+} / \mathrm{DAPI}^{+}$or $\mathrm{Tuj} 1^{+} / \mathrm{DAPI}^{+}$at day $9(\mathbf{f}){ }^{\star} P<0.05$, unpaired, two tailed Student's $t$-tests versus ANLmp for the same category; $n=6$ wells from 3 independent experiments for each condition.

infected with ANL, ANLm, ANLp or ANLmp were pulse labelled with EdU for 2 at $24 \mathrm{~h}$ after Dox induction and were cultured to the completion of reprogramming. At day 9, the percentage of $\mathrm{EdU}^{+}$cells, which were in S phase at $24 \mathrm{~h}$ after DOX induction, was significantly increased by p53 knockdown in ANLp or ANLmp, compared with ANL or ANLm $(P<0.05$, unpaired, two-tailed Student's $t$-tests; Fig. 3b). However, only about $1.5-2 \%$ of all cells were double positive for Tuj1 and EdU (Fig. 3c,e-h) and about $0.5-1 \%$ of all cells were double positive for $\mathrm{TH}$ and EdU (Fig. 3d,i-l), no matter what combinations of viruses were used $(P>0.05)$. The vast majority of EdU ${ }^{+}$cells did not become Tuj $1^{+}$or $\mathrm{TH}^{+}$neurons.

These findings made us realize that we need to reduce the percentage of cells in $S$ phase to promote reprogramming. This could be easily achieved by culturing virus-infected cells in Dulbecco's modified eagle medium (DMEM)/F12 media without serum for $24 \mathrm{~h}$ (Fig. $3 \mathrm{~m}$ ). After serum withdrawal, uninfected (Fig. 3n) or ANLmp-infected fibroblasts (Fig. 3o) were arrested at the G1 phase, with significantly fewer percentages of cells in $S$ and $\mathrm{G} 2 / \mathrm{M}$ phases. Accordingly, the percentage of $\mathrm{EdU}^{+}$cells at this condition was lowered to $8.9 \pm 0.7 \%$ (Fig. $3 p$ and Supplementary
Fig. 5d). Dox induction for $24 \mathrm{~h}$ further decreased the percentage of EdU ${ }^{+}$cells to $5.5 \pm 0.4 \%$ (Fig. $3 p$ and Supplementary Fig. $5 \mathrm{~h}$ ). Serum withdrawal and Dox induction of ANL or ANLm achieved greater reduction in the percentage of $\mathrm{EdU}^{+}$cells, as p53 knockdown in ANLp or ANLmp promoted more cells to enter the $S$ phase (Fig. 3p and Supplementary Fig. 5). With cell cycle arrest at G1 induced by serum withdrawal, ANLmp produced markedly more Tuj1 ${ }^{+}$cells and $\mathrm{TH}^{+}$cells at day 10 (Fig. 3q). None of these neurons was $\mathrm{EdU}^{+}$(Fig. 3r,s), as the percentage of $S$ phase cells was already reduced markedly by serum withdrawal at the start of reprogramming.

G1 arrest by different methods all enhances the conversion. To substantiate the effect of G1 arrest on the transdifferentiation, we cultured ANLmp-infected MRC5 cells for $24 \mathrm{~h}$ in $10 \%$ fetal bovine serum (FBS) or serum plus SU9516 $(5 \mu \mathrm{M})$, a selective inhibitor of CDK2 (ref. 31). We then added Dox to initiate reprogramming in full media (see below) without or with SU9516 for another $24 \mathrm{~h}$. SU9516 significantly increased reprogramming efficiency (Fig. 4c) and yield (Fig. 4d), compared with the situation with $10 \%$ FBS alone (Fig. $4 \mathrm{a}-\mathrm{d}$ ). The number of DAPI ${ }^{+}$cells was not significantly affected by $48 \mathrm{~h}$ treatment of SU9516 (Fig. 4d), which did not significantly increase cell death during the course of reprogramming. This is in sharp contrast to the constitutive expression of $\mathrm{p} 21$, which greatly reduced $\mathrm{DAPI}^{+}$ non-neural cells through increased cell death (Fig. 2a,e). When we performed the same experiments with serum withdrawal during the $24 \mathrm{~h}$ before Dox addition, we found that SU9516 did not further increase the conversion of fibroblasts to iDA neurons (Fig. 4e-h). The effect of SU9516 was occluded by serum withdrawal.

Furthermore, we used Torin1, a highly selective mTOR inhibitor to arrest cell cycle at the G1/S checkpoint ${ }^{32,33}$. ANLmp-infected MRC5 cells were treated without or with Torin $1(0.1 \mu \mathrm{M})$ for $24 \mathrm{~h}$ in $10 \%$ FBS. Dox was then added to initiate reprogramming in full media (see below) without or with Torin 1 for another $24 \mathrm{~h}$. Torin 1 significantly increased reprogramming efficiency (Fig. 4k) and yield (Fig. 4l), compared with the situation with $10 \%$ FBS alone (Fig. 4i-l). The total number of $\mathrm{DAPI}^{+}$cells was not significantly changed by the Torin 1 treatment (Fig. 4l). The same experiments were repeated with serum withdrawal during the $24 \mathrm{~h}$ before the addition of Dox. The transdifferentiation-enhancing effect of Torin 1 was occluded by serum withdrawal (Fig. $4 \mathrm{~m}-\mathrm{p}$ ). Thus, G1 arrest induced by three different methods-serum withdrawal, the CDK2 inhibitor SU9516 or the mTOR inhibitor Torin 1-all enhanced the conversion of fibroblasts to iDA neurons.

To examine the effects of cell quiescence, ANLmp-infected MRC5 cells were maintained for 4 days in DMEM media with $0.1 \%$ FBS to induce quiescence ${ }^{34,35}$. Dox was then added to initiate reprogramming in full media. After another 9 days, cells were fixed and stained for Tuj1, TH and DAPI (Supplementary Fig. 6a,b). Reprogramming efficiency (Supplementary Fig. 6c) and yield (Supplementary Fig. 6d) were significantly decreased when quiescent, rather than G1-arrested MRC5 cells, were used $(P<0.05$, unpaired, two-tailed Student's $t$-tests). This is consistent with studies showing that quiescent fibroblasts are much harder to reprogram by MyoD to myocytes ${ }^{34,35}$. To examine the impact of cell senescence, we converted MRC5 cells at passage 1 or passage 10 to iDA neurons (Supplementary Fig. 6e,f) and found that reprogramming efficiency (Supplementary Fig. 6g) and yield (Supplementary Fig. 6h) were significantly reduced by cellular senescence, which manifested in the significantly slower cell proliferation rate of MRC5 cells at 



7

10
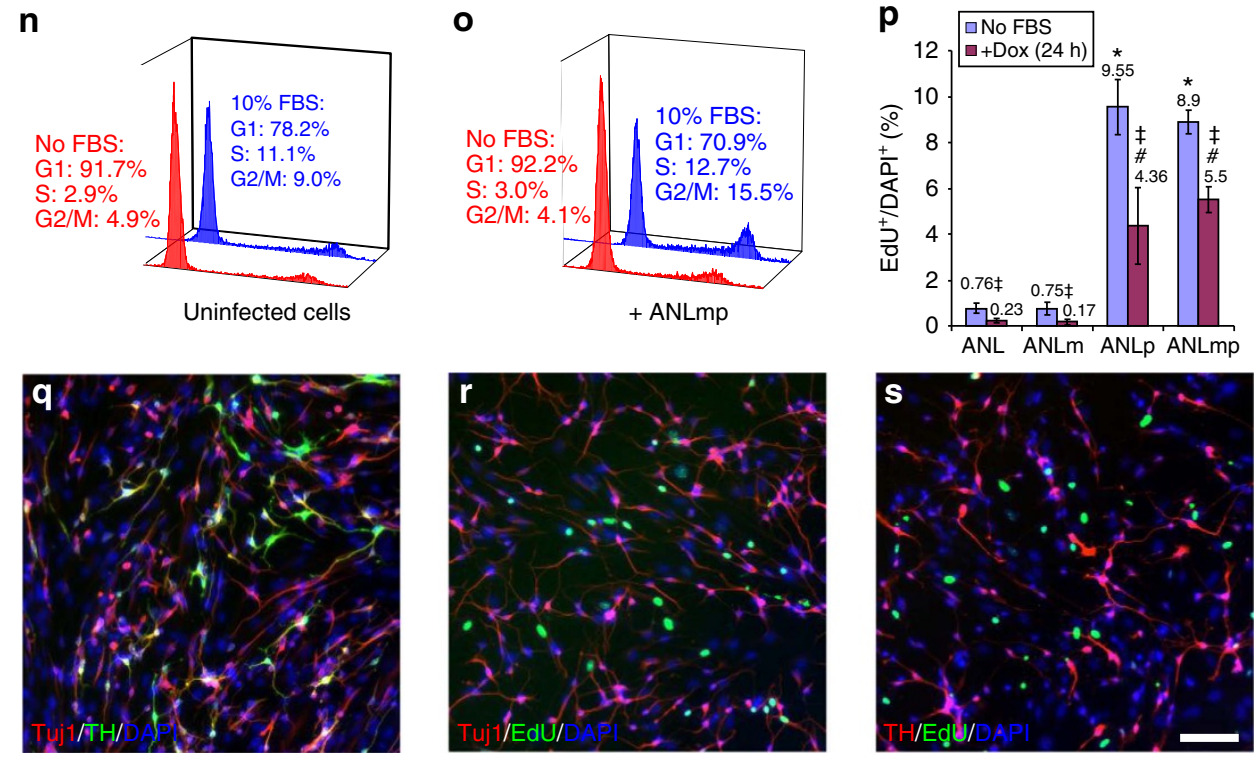

Figure 3 | G1 arrest facilitates fibroblast-to-iDA conversion. (a) The percentage of EdU-labelled cells after Dox induction of the indicated reprogramming factors for 0,24 and 48 h. ${ }^{\star} P<0.01$, unpaired, two tailed Student's $t$-tests versus 0 h; $n=6$ wells from 3 independent experiments for each condition. (b-d) The percentage of $\mathrm{EdU}^{+}$cells in all $\mathrm{DAPI}^{+}$cells $(\mathbf{b})$, the percentage of $\mathrm{EdU}^{+} \mathrm{Tuj}^{+}{ }^{+}$double-positive cells in all $\mathrm{DAPI}^{+}$cells $(\mathbf{c})$ and the percentage of EdU ${ }^{+} \mathrm{TH}^{+}$ double-positive cells in all $\mathrm{DAPI}^{+}$cells (d) at day 9 of reprogramming with the indicated factors. ${ }^{\star} P<0.05$, unpaired, two tailed Student's $t$-tests versus ANL or ANLm; $n=6$ wells from 3 independent experiments. Representative images of cells co-stained for Tuj1/EdU/DAPI (e-h) or TH/EdU/DAPI (i-I) at day 9 of reprogramming with the indicated factors. (m) Improved protocol using serum withdrawal for $24 \mathrm{~h}$ in DMEM/F12 to arrest cell cycle at G1 before Dox induction of reprogramming factors in neural induction media. Cell cycle analysis for MRC5 cells ( $\mathbf{n}$ ) or MRC5 cells transduced with ANLmp viruses (0) in the presence or absence of fetal bovine serum (FBS). (p) Percentage of EdU-labelled cells after serum withdrawal and treatment without or with Dox for $24 \mathrm{~h}$ for the indicated reprogramming factors. ${ }^{\ddagger} P<0.05$, unpaired, two tailed Student's $t$-tests versus the preceding bar. ${ }^{\star}{ }^{\#} P<0.05$, unpaired, two tailed Student's $t$-tests versus ANL without or with Dox, respectively; $n=6$ wells from 3 independent experiments. (q) $\mathrm{TH}^{+}$and Tuj ${ }^{+}$neurons generated with the protocol in $\mathbf{m}$. Lack of EdU labelling in Tuj ${ }^{+}$neurons $(\mathbf{r})$ and $\mathrm{TH}^{+}$neurons (s) derived from the protocol in $\mathbf{m}$. Pulse labelling of EdU (for $2 \mathrm{~h}$ ) was performed at $24 \mathrm{~h}$ in Dox treatment. Staining was done at day 10 . Scale bars, $100 \mu \mathrm{m}$. 

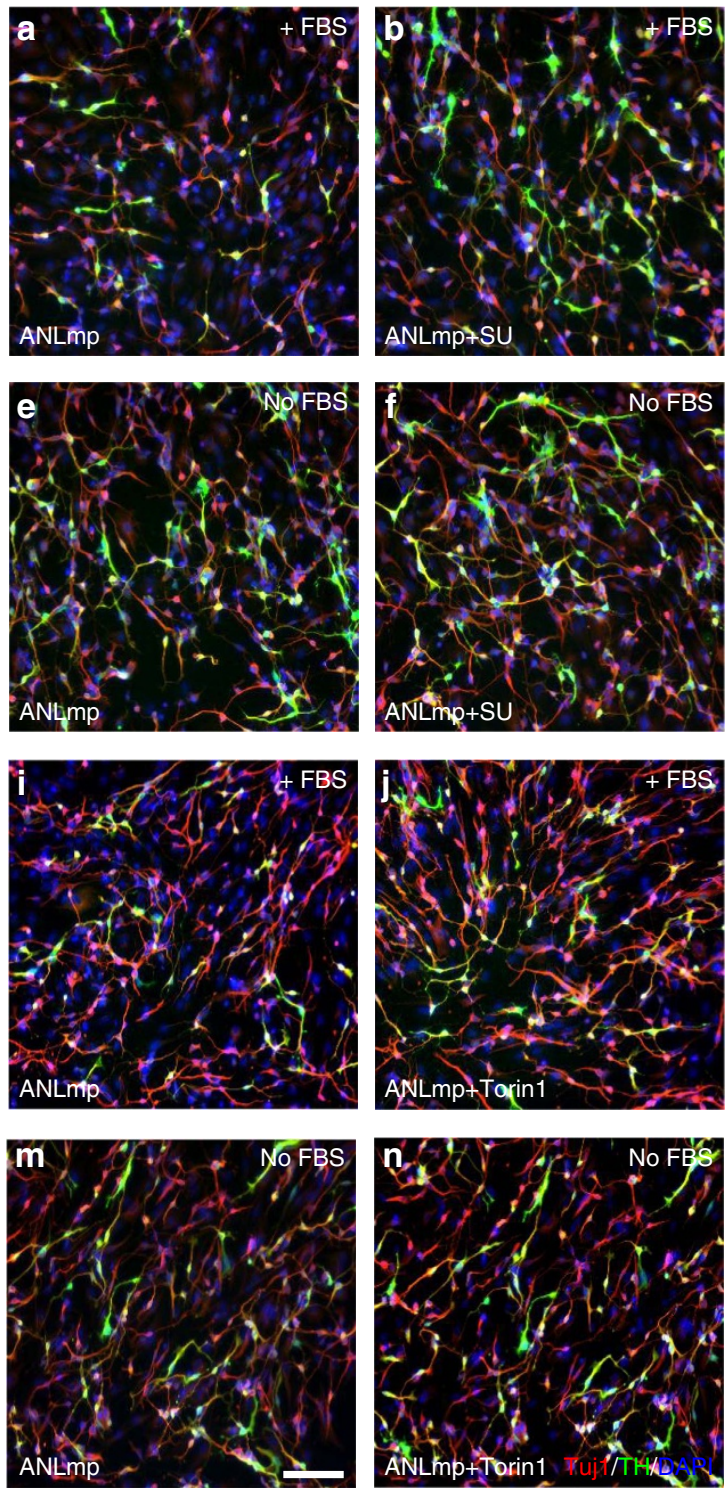
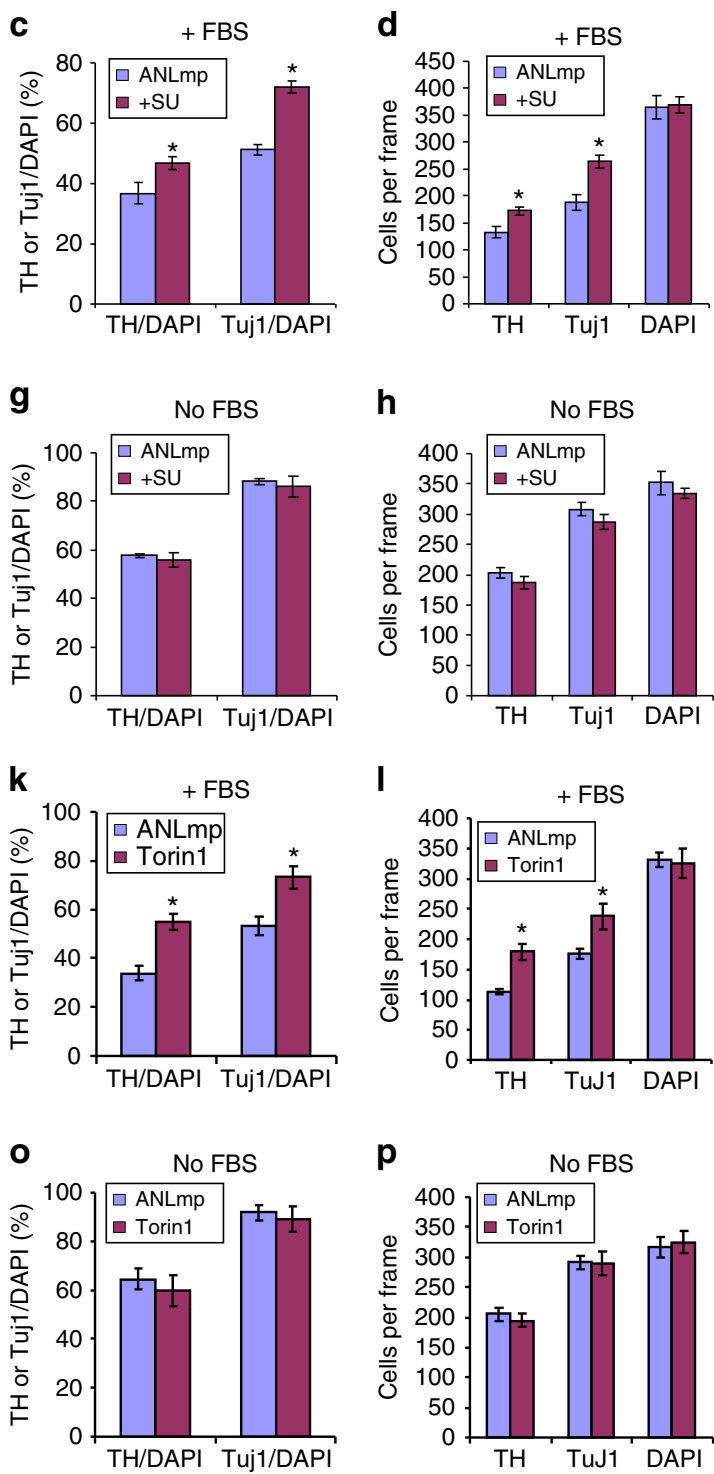

Figure 4 | G1 arrest by different mechanisms enhances the transdifferentiation. (a-d) Representative images of MRC5 cells reprogrammed in full media by ANLmp in the presence of fetal bovine serum (FBS) without (a) or with the CDK2 inhibitor SU9516 (SU, $5 \mu \mathrm{M}$ for $48 \mathrm{~h}$ ) (b). The percentage of TH ${ }^{+}$or $\mathrm{Tuj}^{+}{ }^{+}$cells in all cells $\left(\mathrm{DAPI}^{+}\right)(\mathbf{c})$ and the number of $\mathrm{TH}^{+}, \mathrm{Tuj}^{+}$or DAPI ${ }^{+}$cells per frame under $\times 10$ lenses $(\mathbf{d})$ were analysed at day $10 .{ }^{\star} P<0.05$, unpaired, two tailed Student's $t$-tests versus the preceding bar; $n=6$ wells from 3 independent experiments. (e-h) Representative images of MRC 5 cells reprogrammed in full media by ANLmp in the absence of FBS without (e) or with the CDK inhibitor SU9516 (SU, $5 \mu \mathrm{M} \mathrm{for} 48 \mathrm{~h}$ ) (f). The percentage of TH ${ }^{+}$ or Tuj $1^{+}$cells in all cells $\left(\mathrm{DAPI}^{+}\right)(\mathbf{g})$ and the number of $\mathrm{TH}^{+}, \mathrm{Tuj}^{+}$or DAPI ${ }^{+}$cells per frame under $\times 10$ lenses (h) were analysed at day 10 .

(i-I) Representative images of MRC5 cells reprogrammed in full media by ANLmp in the presence of FBS without (i) or with the mTOR inhibitor Torin 1 $(0.1 \mu \mathrm{M}$ for $48 \mathrm{~h})(\mathbf{j})$. The percentage of $\mathrm{TH}^{+}$or Tuj $1^{+}$cells in all cells $\left(\mathrm{DAPI}^{+}\right)(\mathbf{k})$ and the number of $\mathrm{TH}^{+}, \mathrm{Tuj}^{+}{ }^{+}$or DAPI ${ }^{+}$cells per frame under $\times 10$ lenses (I) were analysed at day 10. ${ }^{\star} P<0.05$, unpaired, two tailed Student's $t$-tests versus the preceding bar; $n=6$ wells from 3 independent experiments. Representative images of MRC5 cells reprogrammed in full media by ANLmp in the absence of FBS without (m) or with the mTOR inhibitor Torin 1 $(0.1 \mu \mathrm{M}$ for $48 \mathrm{~h})(\mathbf{n})$. The percentage of $\mathrm{TH}^{+}$or Tuj $1^{+}$cells in all cells $\left(\mathrm{DAPl}{ }^{+}\right)(\mathbf{o})$ and the number of $\mathrm{TH}^{+}, \mathrm{Tuj}^{+}$or DAPI $^{+}$cells per frame under $\times 10$ lenses (p) were analysed at day 10 . Scale bar, $100 \mu \mathrm{m}$.

passage 10 versus that at passage 1 (Supplementary Fig. 6i; $P<0.05$, unpaired, two-tailed Student's $t$-tests).

Synergistic actions of media additives on the conversion. In our initial reprogramming experiments, we used neural induction media $^{25}$ that contained basic fibroblast growth factor (bFGF, $20 \mathrm{ng} \mathrm{ml}^{-1}$ ) and many other small-molecule compounds and growth factors (see Methods). When we performed cell cycle analysis on ANLmp-infected fibroblasts that were treated with Dox in this media for $24 \mathrm{~h}$, we found that bFGF in neural induction media promoted cell cycle entry in the absence of serum (Fig. 5a). By replacing bFGF with nerve growth factor (NGF, $20 \mathrm{ng} \mathrm{ml}^{-1}$ ), we found that the new media (termed full media) maintained cell cycle arrest at G1 (Fig. 5a) and significantly increased the efficiency in the conversion of human fibroblasts to neurons $(P<0.05$, unpaired, two-tailed Student's $t$-tests). At day 10 in full media with NGF, $93.3 \pm 1.6 \%$ of all cells were Tuj $1^{+}$and $59.2 \pm 3.7 \%$ of all cells were $\mathrm{TH}^{+}$, while the percentage of Tuj $1^{+}$or $\mathrm{TH}^{+}$cells was $68.9 \pm 6.7 \%$ or $31.7 \pm 2.8 \%$, respectively, in the same media with bFGF instead of NGF (Fig. 5b). Representative phase contrast image (Fig. 5c) and 
immunostaining (Fig. 5d) showed that reprogramming with full media produced a very high percentage of neurons, with many of them expressing TH. We found that Dox induction from day 1 to day 7 achieved the best results (Supplementary Fig. 7a,b). The rapid pace of reprogramming is shown in Supplementary Fig. $7 d-i$.

The different effects of bFGF and NGF led us to systematically examine the impact of various additives in full media. Comparing with the situation using basal media (DMEM/F12 with B27 and N2 supplements), reprogramming efficiency was improved by the singular addition of the ROCK inhibitor Y27632 $(10 \mu \mathrm{M})^{36}$,

a


$\mathbf{f}$


CHIR99021 (CHIR, $3 \mu \mathrm{M})^{37}$, vitamin C (VC, $\left.0.2 \mathrm{mM}\right)^{38}$, dorsomorphin $(\mathrm{DM}, 1 \mu \mathrm{M})^{39}, \mathrm{SB} 431542(\mathrm{SB}, 10 \mu \mathrm{M})^{40}$, purmorphamine (Pur, $2 \mu \mathrm{M})^{41}$, NGF $\left(20 \mathrm{ng} \mathrm{ml}^{-1}\right)$, glial cell line-derived neurotrophic factor (GDNF; $\left.20 \mathrm{ng} \mathrm{ml}^{-1}\right)^{25}$, brain-derived neurotrophic factor (BDNF; $\left.20 \mathrm{ng} \mathrm{ml}^{-1}\right)^{25}$ or transforming growth factor (TGF) $\beta 3\left(1 \mathrm{ng} \mathrm{ml}^{-1}\right)^{25}$. However, the most remarkable improvement was found when all these factors were included in the full media (Fig. 5e). Representative images and reprogramming yields were shown in Supplementary Fig. $8 \mathrm{a}-\mathrm{o}$. TGF $\beta 3$ also activates the p38 MAP kinase pathway ${ }^{42}$ to support the differentiation of midbrain DA neurons ${ }^{43}$. At $10 \mu \mathrm{M}$, SB431542 only partially inhibits TGF $\beta$ signalling in the differentiation of midbrain DA neurons ${ }^{44}$, as TGF $\beta 3$ can bind to type II TGF receptors, without the need for type I receptors ${ }^{45}$, which SB431542 blocks ${ }^{46}$.

To explore whether additives in full media facilitate the conversion per se or enhance the survival of converted cells, we used basal media and full media at different time points. As shown in Fig. 5f, there was no significant difference in reprogramming efficiency when the first 1 or 2 days of Dox treatment were in basal media (condition 6 or 5 , respectively) or in full media (condition 7), as long as the later days were in full media. Prolonged incubation of the cells (3 days or more) in basal media significantly decreased reprogramming efficiency $(P<0.05$, unpaired, two-tailed Student's $t$-tests). Reprogramming yields were consistent with reprogramming efficiency, as the total numbers of cells (DAPI ${ }^{+}$) were not significantly affected by the seven conditions $(P>0.05$, unpaired, two-tailed Student's $t$-tests; Supplementary Fig. 8p-r). By day 3, most of the cells already assumed neuronal morphology (Supplementary Fig. 7f). The rapid pace of conversion suggests that an intrinsic programme is being executed during the first 2 days of Dox treatment. The lack of effects of the media additives during the rapid conversion suggests that they improve reprogramming largely by promoting survival of converted cells.

With or without p53 knockdown, serum withdrawal increased reprogramming efficiency for all combinations of reprogramming factors (ANL, ANLp, ANLm and ANLmp; Supplementary Fig. 9a-h versus Fig. 1b-f), suggesting that the transdifferentiation-enhancing effects exerted by G1 arrest and p53 knockdown are independent. To substantiate the results from MRC5 cells

Figure 5 | Neurotrophic factors and small-molecule compounds augment the conversion. (a) ANLmp-transduced MRC5 cells were cultured in the absence of serum for $24 \mathrm{~h}$ (black line) and treated with NGF and Dox (green line) or bFGF and Dox (red line) for another $24 \mathrm{~h}$. Cell cycle analysis by propidium iodide staining was performed on these cells. (b-d) The percentage of $\mathrm{TH}^{+}$or Tuj ${ }^{+}$neurons at day 10 in neural induction media containing bFGF or NGF (that is, full media) (b) ${ }^{\star},{ }^{\#} P<0.01$, unpaired, two tailed Student's t-tests versus $\mathrm{TH}^{+}$or $\mathrm{Tuj}^{+}{ }^{+}$in bFGF, respectively; $n=6$ wells from 3 independent experiments. Representative phase contrast image (c) and immunostaining (d) of neurons generated in full media containing NGF. Scale bars, $10 \mu \mathrm{m}$. (e) The percentage of $\mathrm{TH}^{+}$or $\mathrm{Tuj}^{+}$ neurons at day 10 in basal media without or with various small molecule compounds and neurotrophic factors. B27, B27 supplements; VC, vitamin C; DM, dorsomorphin; SB, SB431542; CHIR, CHIR99021; Pur, Purmorphamine; $N G F$, nerve growth factor; GDNF, glial cell line-derived neurotrophic factor; $\mathrm{BDNF}$, brain-derived neurotrophic factor; TGF $\beta 3$, transforming growth factor $\beta 3$; Y27632, rock inhibitor; Full, all of the above. ${ }^{\star}{ }^{\#} P<0.05$, unpaired, two tailed Student's $t$-tests versus $\mathrm{TH}^{+}$or Tuj ${ }^{+}$in B27 alone, respectively; $n=6$ wells from 3 independent experiments for each condition. (f) The percentage of $\mathrm{TH}^{+}$or Tuj ${ }^{+}$neurons at day 10 when basal media and full media were used at different time as indicated. ${ }^{\star},{ }^{\#} P<0.05$, unpaired, two tailed Student's $t$-tests versus $\mathrm{TH}^{+}$or $\mathrm{Tuj}^{+}$for condition 7 , respectively; $n=6$ wells from 3 independent experiments for each condition. 
(fetal, male; Supplementary Fig. 9h), we reprogrammed additional lines of normal human primary fibroblasts including IMR90 (fetal, female; Supplementary Fig. 9i), CCD-19 LU (20 years, female; Supplementary Fig. 9j), AG22056 (newborn, male; Supplementary Fig. 9k,n), AG16146 (31 years, male; Supplementary Fig. 9l,n) and GM00731 (96 years, male; Supplementary Fig. 9m,n), using ANLmp and serum withdrawal. Fetal fibroblasts (MRC5 and IMR90) behaved the same way (Supplementary Fig. 9h,i), while fibroblasts from adults (CCD-19Lu, AG16146 and GM00731) and the newborn (AG22056) showed reduced conversion efficiency (Supplementary Fig. $9 \mathrm{j}-\mathrm{n}$ ), as has been similarly found in other studies ${ }^{10,11}$. The effect of miR124 on enhancing the morphology of iDA neurons (Fig. 1b-e,i,j) became more apparent when conversion was done without serum (Supplementary Fig. 9a versus c or Supplementary Fig. 9b versus d). In addition, miR124 significantly increased the efficiency of conversion (Fig. If for cells in serum) and much more so with serum withdrawal (Supplementary Fig. 9h-j; $P<0.05$, unpaired, two-tailed Student's $t$-tests). Individually, the effect of miR124, p53shRNA, G1 arrest or media additives was relatively small. However, they were additive so that the accumulative effects were very substantial, raising the efficiency 9.4-fold for $\mathrm{TH}^{+}$cells (Supplementary Fig. 10a) and 5.2-fold for Tuj $1^{+}$cells (Supplementary Fig. 10b). The effect of p53 knockdown on the conversion was substantiated by co-expressing p53 shRNA and green fluorescent protein (GFP) in a bicistronic vector (pLKO.3G). The percentage of Tuj1 ${ }^{+}$cells in $\mathrm{GFP}^{+}$cells was much higher than that in $\mathrm{GFP}^{-}$cells (Supplementary Fig. 10c). The same was true for the percentage of $\mathrm{TH}^{+}$cells (Supplementary Fig. 10d). The best time to freeze the cells was at $24 \mathrm{~h}$ of serum withdrawal. ANLmp-infected MRC5 cells were cultured for $24 \mathrm{~h}$ without serum and then frozen for 7 days. After cells were thawed, Dox was added to reprogram the cells in full media for another 9 days. Conversion efficiency and yield were comparable to the situation where cells were reprogrammed without freezing (Supplementary Fig. 11). Once reprogramming was initiated by Dox, freezing the cells at any point caused lots of cell death.

The conversion of fibroblasts to iDA neurons depends on Tet1. The very high levels of $5 \mathrm{hmC}$ in neurons ${ }^{20}$ and the critical role of Tet proteins in epigenetic reprogramming, such as the derivation of iPSCs ${ }^{21}$, led us to explore the potential role of Tet proteins in the direct conversion of fibroblasts to iDA neurons. MRC5 cells were reprogrammed with lentiviruses expressing ANLmp and shRNA against scrambled control sequence (Fig. 6a), Tet1 (Fig. 6b), Tet2 (Fig. 6c) or Tet3 (Fig. 6d). Knocking down each Tet, particularly Tet1, greatly reduced the numbers of $\mathrm{TH}^{+}$cells, Tuj ${ }^{+}$cells and DAPI ${ }^{+}$cells (Fig. 6e), due to large amounts of cell death. The percentages of $\mathrm{TH}^{+}$or Tuj1 ${ }^{+}$ cells in $\mathrm{DAPI}^{+}$cells were also severely decreased, when compared with those produced by ANLmp alone or ANLmp plus scrambled shRNA (Fig. 6f). Real-time quantitative reverse transcription-PCR (qRT-PCR) measurement of Tet1, Tet2 or Tet3 level in MRC5 cells transduced with lentivirus expressing shRNA against scrambled sequence, Tet 1 , Tet 2 or Tet 3 for 3 days showed that each of the Tet genes was significantly knocked down (Fig. 6g).

As p53 knockdown significantly enhanced the conversion of fibroblasts to iDA neurons (Fig. 1), we measured the level of Tet1, Tet 2 or Tet 3 by qRT-PCR in MRC5 cells transduced with p53 shRNA for 1 day. The mRNA level of p53 was greatly reduced by the p53 shRNA lentivirus, while the expression of Tet1, but not Tet 2 or Tet3, was significantly increased $(P<0.05$, unpaired, two-tailed Student's $t$-tests; Fig. $6 \mathrm{~h})$. Next, we examined the impact of serum withdrawal on Tet expression and found that the mRNA levels of Tet 1 and Tet 2 , but not Tet 3 , were significantly increased in MRC5 cells cultured in the absence of serum for $24 \mathrm{~h}$ $(P<0.05$, unpaired, two-tailed Student's $t$-tests; Fig. 6i). When MRC5 cells were transduced with p53 shRNA and cultured without serum for $24 \mathrm{~h}$, there was an even higher induction of Tet1 and Tet2, but not Tet3 (Fig. 6j). Infection of ANLmp lentiviruses did not significantly induce Tet genes further (Fig. 6j). However, Dox-induced expression of ANLm for 2 days (p53 shRNA was constitutively expressed) led to a huge increase in the expression of Tet 1 and Tet2, as well as Tet 3 to a lesser extent (Fig. 6j). Thus, manipulations that promoted the transdifferentiation (p53 knockdown, serum withdrawal and induction of reprogramming factors) synergistically converged on the induction of Tet 1 and Tet 2 . We also compared the impact of basal media and full media on Tet expression by inducing the expression of ANLmp with Dox for 2 days in the two different media. The two media had no significant difference on the mRNA level of Tet1, Tet 2 or Tet3 $(P>0.05$, unpaired, two-tailed Student's $t$-tests; Fig. 6k). This is consistent with the observation that full media promoted neuronal survival rather than conversion per se (Fig. 5f).

Using serum withdrawal and full media, MRC5 cells were reprogrammed to iDA neurons with ANLmp (Fig. 61), ANLmp plus Tet1 (Fig. 6m), Tet2 (Fig. 6n) or Tet3 (Fig. 6o). Tet1, but not Tet 2 or Tet3, significantly increased reprogramming yield (Fig. 6p). Tet1 increased the number of DAPI ${ }^{+}$cells per frame by 47 (from 225 to 272), Tuj1 ${ }^{+}$cells by 50 (from 198 to 248) and $\mathrm{TH}^{+}$cells by 35 (from 130 to 165). Thus, all Tetl-induced increase of $\mathrm{DAPI}^{+}$cells was due to increased number of Tuj ${ }^{+}$ neurons, $70 \%$ of which was $\mathrm{TH}^{+}$neurons. As the loss of cells during reprogramming by ANLmp was visibly reduced by Tet1, the increased numbers of Tuj $1^{+}$cells, $\mathrm{TH}^{+}$cells and DAPI ${ }^{+}$ cells rendered the ratio of $\mathrm{TH}^{+} / \mathrm{DAPI}^{+}$or $\mathrm{Tuj}^{+} / \mathrm{DAPI}^{+}$not significantly changed (Fig. 6q). The level of $5 \mathrm{hmC}$ was significantly increased by induction of ANLmp for 2 days. The effect was further enhanced by Tet1 and abolished by Tet1 shRNA (Fig. 6r). Mouse or human Tet genes had no significant difference in their effects on this transdifferentiation. The

\footnotetext{
Figure 6 | The conversion is dependent on Tet1. (a-d) MRC5 cells reprogrammed with ANLmp and shRNA against scrambled sequence (Con_shRNA) (a), Tet1 (b), Tet2 (c) or Tet3 (d) were stained for Tuj1, TH and DAPI. (e, f) Reprogramming yield (e) and efficiency (f). ${ }^{\star} P<0.05$, unpaired, two tailed Student's $t$-tests versus ANLmp; $n=6$ wells from 3 independent experiments. (g) mRNA levels of Tet genes in MRC5 cells transduced with shRNA against control sequence, Tet1, Tet2 or Tet3. ${ }^{\star} P<0.05$, unpaired, two tailed Student's $t$-tests versus the preceding bar; $n=6$. (h) mRNA levels of p53 and Tet genes in MRC5 cells transduced with control shRNA or $p 53$ shRNA. ${ }^{\star} P<0.05$, unpaired, two-tailed Student's $t$-tests versus the preceding bar; $n=6$. (i) mRNA levels of Tet genes in MRC5 cells with or without $10 \%$ FBS for $24 \mathrm{~h} .{ }^{\star} P<0.05$, unpaired, two-tailed Student's $t$-tests versus the preceding bar; $n=6$. (j) MRC5 cells were treated as indicated to measure mRNA levels of Tet genes. ${ }^{\star} P<0.05$ versus the first bar for each Tet gene; ${ }^{\#} P<0.05$ versus the second or third bar for each Tet gene; ${ }^{\star \star} P<0.05$ versus all other bars for each Tet gene; $n=6$, all with unpaired, two-tailed Student's $t$-tests. (k) mRNA levels of Tet genes in ANLmp-infected MRC5 cells reprogrammed in basal media or full media for 2 days; $n=6$. (I-o) MRC5 cells reprogrammed with ANLmp (I) or ANLmp plus Tet1 (m), Tet2 (n) or Tet3 (o) were stained for Tuj1, TH and DAPI. (p, q) Reprogramming yield (p) and efficiency (q). ${ }^{\star} P<0.05$, unpaired, two-tailed Student's $t$-tests versus ANLmp for the same category; $n=6$. (r) $5 \mathrm{hmC}$ dot blot of genomic DNA from MRC 5 cells reprogrammed as indicated for 2 days. Blots from 200 ng DNA were quantified. ${ }^{\star} P<0.05$, unpaired, two-tailed Student's $t$-tests versus ANLmp alone; $n=3$ independent experiments. Scale bar, $100 \mu$ m.
} 
expression and localization of exogenous human Tet1, Tet2 and Tet3 (Supplementary Fig. 12) were similar to those of the mouse homologues ${ }^{47,48}$. Together, the data suggest that the conversion of human fibroblasts to iDA neurons requires Tet1.
Functional characterization of iDA neurons. The $\mathrm{TH}^{+}$cells co-expressed dopaminergic markers AADC (Fig. 7a), ALDH1A1 (Fig. 7b), DAT (Fig. 7c), VMAT2 (Fig. 7d), Pitx3 (Fig. 7e), Nurr1 (Fig. 7f), midbrain markers FoxA2 (Fig. 7g) and En1 (Fig. 7h),


j
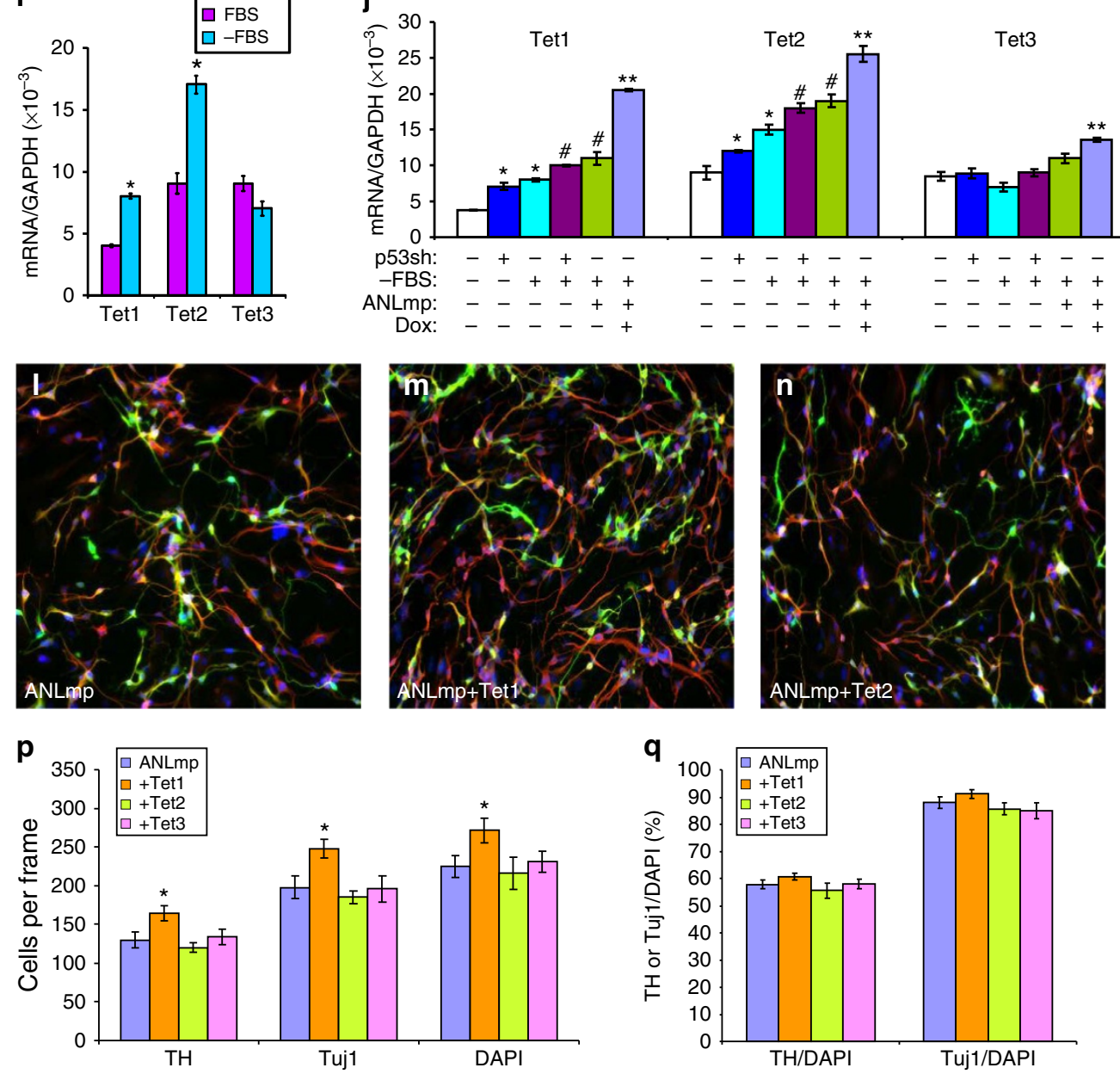
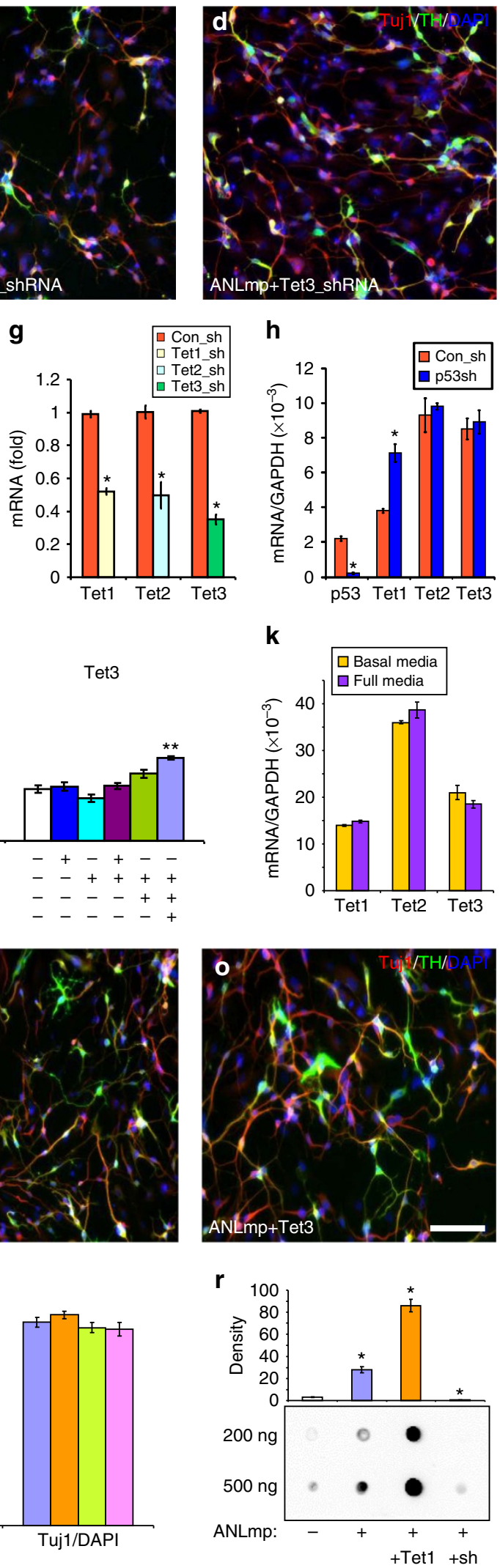

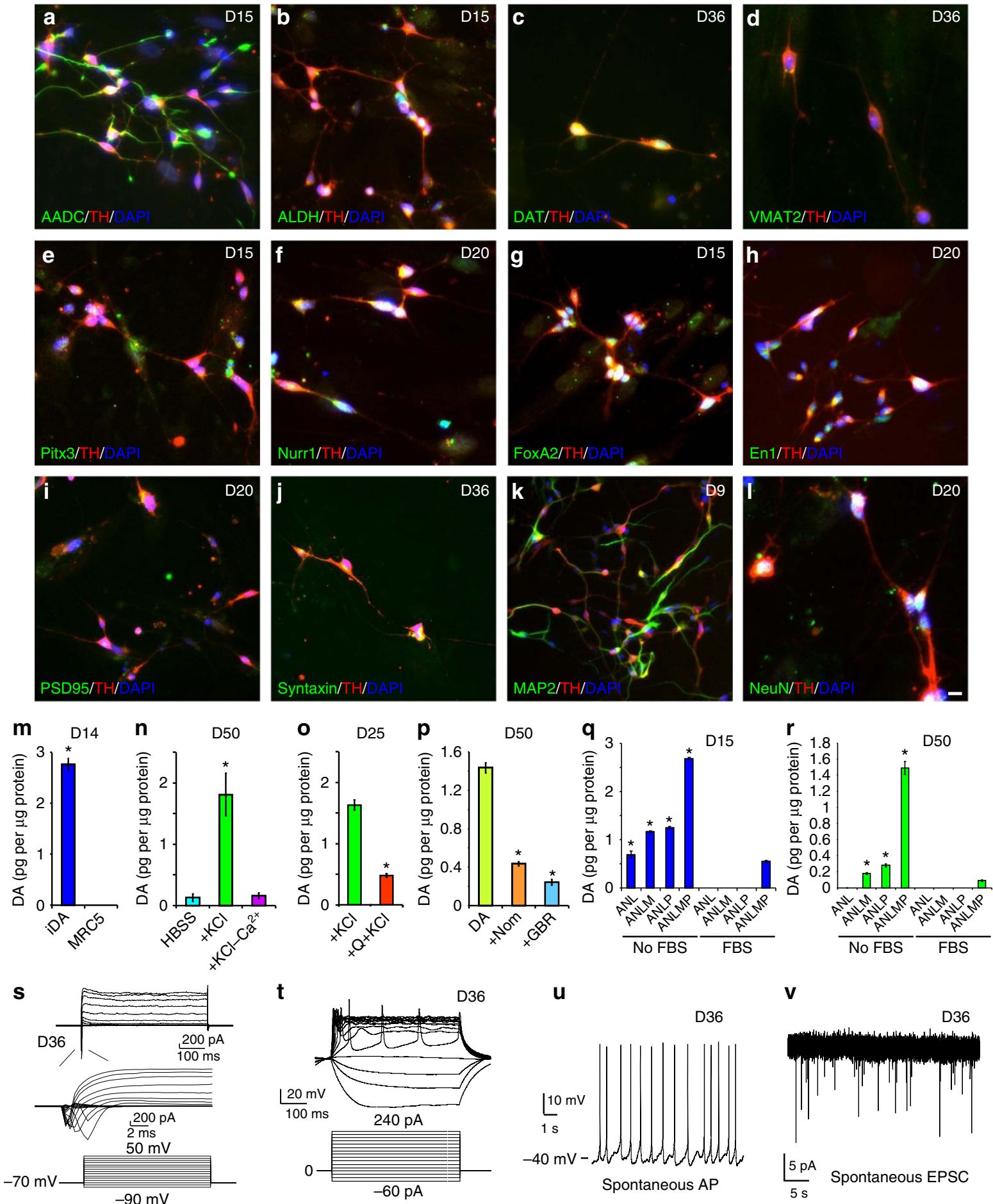

Figure 7 | Characterization of iDA neurons. (a-I) Co-staining of iDA neurons with antibodies against TH and dopaminergic markers AADC (a), ALDH1A1 (b), DAT (c), VMAT2 (d), Pitx3 (e) and Nurr1 (f), or midbrain neuronal markers FoxA2 (g) and engrailed 1 (En1) (h), or synaptic markers PSD95 (i) and syntaxin $1(\mathbf{j})$, or markers for mature neurons MAP2 (k) and NeuN (I). Scale bar, $10 \mu \mathrm{m}$. ( $\mathbf{m})$ The amount of endogenous dopamine in the iDA neurons and the original fibroblasts. ${ }^{\star} P<0.01$, unpaired, two-tailed Student's $t$-tests versus fibroblast; $n=6$ wells from 3 independent experiments. (n) Dopamine release from iDA neurons in Hank's balanced salt solution (HBSS), HBSS with $\mathrm{KCl}(56 \mathrm{mM})$ or $\mathrm{Ca}^{2}{ }^{+}$-free $\mathrm{HBSS}$ with $\mathrm{KCl}(56 \mathrm{mM}) .{ }^{\star} P<0.01$, unpaired, two-tailed Student's $t$-tests versus HBSS without $\mathrm{KCl} ; n=6$ wells from 3 independent experiments. (o) $\mathrm{KCl}$-induced dopamine release in the absence or presence of the dopamine D2-class agonist quinpirole $(\mathrm{Q}, 1 \mu \mathrm{M})$. ${ }^{\star} P<0.01$, unpaired, two-tailed Student's $t$-tests; $n=6$. (p) Dopamine uptake by iDA neurons for $5 \mathrm{~min}$ in the absence or presence of the selective DAT inhibitor nomifensine $(10 \mu \mathrm{M})$ or GBR12909 $(10 \mu \mathrm{M})$. ${ }^{\star} P<0.01$, unpaired, two-tailed Student's $t$-tests versus DA alone; $n=6$ wells from 3 independent experiments. $(\mathbf{q}, \mathbf{r})$ Dopamine content $(\mathbf{q})$ or $\mathrm{KCl}$-induced dopamine release $(\mathbf{r})$ in iDA neurons generated with various factors and with or without serum withdrawal. FBS, fetal bovine serum. ${ }^{\star} P<0.01$, unpaired, two-tailed Student's $t$-tests versus corresponding condition with FBS; $n=6$ wells from 3 independent experiments. (s) Voltage-gated $\mathrm{Na}^{+}$and $\mathrm{K}^{+}$currents. (t) Response to current injections. (u) Spontaneous action potentials. (v) Spontaneous excitatory postsynaptic currents. Days indicated were from the start of serum withdrawal. 
synaptic markers PSD95 (Fig. 7i) and Syntaxin 1 (Fig. 7j), and mature neuronal markers MAP2 (Fig. 7k) and NeuN (Fig. 7l). Individual channels of the merged images are shown in Supplementary Fig. 13. Co-staining of MRC5-derived iDA neurons at day 10 for Tuj 1 and fibroblast markers such as P4HA1 (prolyl 4-hydroxylase, a key enzyme in collagen synthesis; Supplementary Fig. 14b) or vimentin (Supplementary Fig. 14d) showed that there were very few cells faintly expressing P4HA1 and virtually no cells expressing vimentin. In contrast, MRC5 cells at day 0 showed no expression of Tuj1 and very strong expression of P4HA1 (Supplementary Fig. 14a) and vimentin (Supplementary Fig. 14c). We also co-stained iDA neurons at day 10 for Tuj1, MAP2 and DAPI and found that reprogramming efficiency for neurons, as measured by the ratio of either Tuj1/DAPI or MAP2/DAPI, was not significantly different $(P>0.05$, unpaired, two-tailed Student's $t$-tests; Supplementary Fig. 14e-i). Consistently, when iDA neurons were co-stained for AADC, TH and DAPI, we found that reprogramming efficiency for dopaminergic neurons, as measured by the ratio of either AADC/DAPI or TH/DAPI, was not significantly different $(P>0.05$, unpaired, two-tailed Student's $t$-tests; Supplementary Fig. 14j-n). These results confirmed the specificity of the Tuj1 and $\mathrm{TH}$ antibodies, as well as the validity of our quantification method. The induction of many other neuronal and dopaminergic genes was shown in Supplementary Fig. 15. The induction of microtubule genes (TUBB3 and MAP2) was particularly fast and robust (Supplementary Fig. 15), consistent with the rapid morphological changes (Supplementary Fig. $7 \mathrm{~d}-\mathrm{i}$ ). These results suggest that the $\mathrm{TH}^{+}$cells are midbrain dopaminergic neurons.

Dopamine can be readily measured in the iDA neurons, but not in the parental fibroblasts, by high-performance liquid chromatography (HPLC) coupled with electrochemical detection (Fig. $7 \mathrm{~m}$ ). The iDA neurons released dopamine in response to $\mathrm{KCl}(56 \mathrm{mM}$ for $15 \mathrm{~min})$. The release was completely blocked in $\mathrm{Ca}^{2+}$-free Hank's balanced salt solution (HBSS; Fig. 7n). Dopamine release evoked by $\mathrm{KCl}(56 \mathrm{mM}$ for $15 \mathrm{~min})$ was significantly decreased by the dopamine D2-class agonist quinpirole $(1 \mu \mathrm{M}, 15 \mathrm{~min}$ before and $15 \mathrm{~min}$ overlapping $\mathrm{KCl}$ treatment; Fig. 7o). It demonstrates that the iDA neurons had functional dopamine autoreceptors that serve to downregulate dopamine release ${ }^{49}$. When iDA neurons were treated with quinpirole $(1 \mu \mathrm{M}$ for $10 \mathrm{~min})$, ERK phosphorylation was prominently observed in Tuj ${ }^{+}$neurons and $\mathrm{TH}^{+}$neurons. The effect was completely blocked by the D2-class antagonist sulpiride ( $1 \mu \mathrm{m}$ for $15 \mathrm{~min}$, of which $5 \mathrm{~min}$ was before the addition of quinpirole; Supplementary Fig. 16). The iDA neurons exhibited robust dopamine uptake, which was significantly blocked by the selective inhibitor of dopamine transporter, nomifensine $(10 \mu \mathrm{M})$ or GBR12909 $(10 \mu$ M; Fig. $7 p)$.

To demonstrate that enhanced reprogramming efficiency produced a commensurate increase in function, we measured DA content (Fig. 7q) and KCl-evoked DA release (Fig. 7r) and found that they were markedly higher in iDA neurons derived with our new method, compared with the old method with ANL in the absence of G1 arrest ${ }^{10}$ (Fig. 7q,r). Consistently, protein levels of TH, $\beta 3$-tubulin (Tuj1) and ALDH1A1 were markedly increased by our new method (Supplementary Fig. 17). Electrophysiological recordings showed that the iDA neurons had voltage-dependent $\mathrm{Na}^{+}$and $\mathrm{K}^{+}$currents (Fig. 7s), evoked action potentials (Fig. $7 \mathrm{t}$ ), spontaneous action potentials (Fig. $7 \mathrm{u}$ ) and spontaneous excitatory postsynaptic currents (Fig. 7v). As the iDA neurons maturated, the above electrophysiological properties became more robust (Supplementary Fig. 18 and Supplementary Table 1). Together, these results showed that the human fibroblasts were converted to midbrain DA neurons with active synaptic transmission.

\section{Discussion}

This study discovered three kinetic barriers in the direct conversion of human fibroblasts to iDA neurons by Ascl1, Nurr1, Lmx1a (ref. 10) and miR124 (refs 23,24). First, p53 appears to serve as a major gatekeeper in maintaining the existing transcription network of the cell. When p53 level is reduced by shRNA or MDM2, the conversion became significantly more efficient (Fig. 1). Second, reprogramming of fibroblasts to neurons requires cell cycle exit, as no significant numbers of induced neurons were derived from EdU-labelled cells (Fig. 3). Thus, G1 arrest induced by three independent methods-serum withdrawal (Fig. 3), the CDK2 inhibitor SU9516 (Fig. 4) or the mTOR inhibitor Torin1 (Fig. 4)-all significantly enhanced reprogramming $(P<0.05$, unpaired, two-tailed Student's $t$-tests). Third, the rapid pace of conversion means that cells need to be cultured in a different environment that can sustain the survival and maturation of neuron-like cells. The first 2 days of reprogramming, during which an intrinsic programme appeared to be executed, did not require full media (Fig. 5f and Supplementary Fig. 8p-r). As the cells acquired neuronal characteristics from day 3 or so, they needed full media for survival and maturation.

Our studies showed that Tet1 played a critical role in the epigenetic conversion of human fibroblasts to iDA neurons. The conversion was obliterated by Tet1 knockdown (Fig. 6). Conditions that enhanced the conversion (p53 knockdown, serum withdrawal or expression of reprogramming factors) significantly induced Tetl in a synergistic manner $(P<0.05$, unpaired, two-tailed Student's $t$-tests; Fig. 6). Consistent with these, Tet1 overexpression increased the yield of $\mathrm{TH}^{+}$, Tuj1 ${ }^{+}$ and $\mathrm{DAPI}^{+}$cells, as cell death was visibly reduced (Fig. 6). It seems likely that Tet1, by pushing the epigenome towards a neuronal state, which has the highest $5 \mathrm{hmC}$ content among all cells ${ }^{20}$, may greatly reduce conflicting signals impinging on the cells and thus promote reprogramming and survival of the converted cells. We suspect that the three parameters-cell cycle, p53 and extracellular environment-may be of general importance to cellular reprogramming by defined factors. The systematic identification of the requisite transcription factors, in conjunction with fine tuning of the three parameters, should enable the generation of many types of human cells, and thus tissues, from accessible materials such as fibroblasts.

\section{Methods}

Materials. Nutlin-3a was purchased from Sigma. Dorsomorphin dihydrochloride, SU9516 and Torin1 were from Tocris. Purmorphamine, CHIR 99021 , SB431542 and Y27632 were purchased from Reagents Direct. Recombinant human bFGF, NGF, GDNF, BDNF and TGF $\beta 3$ were purchased from PeproTech. FUW-tetOLoxP, pLKO.1/p53shRNA, pLKO.1/scrambled shRNA, pCAG/p21, pMD2.G and psPAX2 were purchased from Addgene. Human Ascl1 (Genebank accession BC031299), Nurr1 (CV028069) and Lmxla (BC06635) were purchased from OpenBiosystems and subcloned by PCR to the EcoRI site on the FUW-tetO-LoxP vector. Human miR-124 (MIMAT0000422) was amplified from normal human fibroblast genomic DNA and subcloned to the EcoRI site on the FUW-tetO-LoxP vector. FUW-LoxP-M2rtTA was generated by subcloning the BspEI fragment containing the loxP site from FUW-tetO-Loxp-hOCT4 (Addgene) to the BspEI site on the $3^{\prime}$ long terminal repeat of FUW-M2rtTA (Addgene). Human MDM2 complementary DNA (cDNA) was kindly provided by Xinjiang Wang at Roswell Park Cancer Institute and was subcloned to the EcoRI site on the FUW-tetO-LoxP vector. Human p21 was subcloned to the EcoRI site on the FUW vector. Flag-tagged full-length mouse Tet1, Tet 2 or Tet $3 \mathrm{cDNA}^{47}$ was cloned in the Dox-inducible lentiviral vector pTYF-TRE. Human Tet1 cDNA was cloned from MRC5-derived iDA neurons. Human Tet2 cDNA was cloned from leukocytes. Human Tet 3 cDNA was purchased from Addgene. These cDNAs were subcloned to the FUW-tetO-LoxP lentiviral vector. ShRNA against human Tet1, Tet2 or Tet3 
was cloned in pLKO.1. The target sequences for human Tet1, Tet2 and Tet3 are $5^{\prime}$-CCTTGATAGAATCACTCAGTT- ${ }^{\prime}$ (ref. 50), 5' -GGATCATTCTTTGGCCAG A-3' (ref. 51) and $5^{\prime}$-GGAGAAAGATGAAGGTCCA-3' (ref. 51), respectively. All constructs were verified by sequencing.

Generation of iDA neurons from human fibroblasts. Primary human fibroblasts MRC5 and CCD-19 LU (both from American Type Culture Collection), IMR90, AG22056, AG16146 and GM00731 (all from Coriell) were cultured in DMEM containing 10\% FBS and $2 \mathrm{mM}$ L-glutamine. All cell cultures were performed without antibiotics and regularly tested for the absence of mycoplasma by PCR. Lentivirus production and fibroblast infection were performed as described previously ${ }^{25}$. Briefly, lentiviruses were produced by cotransfecting 293FT cells (Life Technologies) in 10-cm dishes with $10 \mu \mathrm{g}$ FUW-tetO-LoxP-cDNA (hAscl1, hNurr1, hLmxla and hmiR-124), or $10 \mu \mathrm{g}$ pLKO.1/p53shRNA, or $10 \mu \mathrm{g}$ FUW-LoxP-M2rtTA with $2.5 \mu \mathrm{g}$ pMD2.G and $7.5 \mu \mathrm{g}$ psPAX2 using Lipofectamine 2000. Lentiviruses generated with the pTYF vector were produced by cotransfection of pTYF-mTet1, mTet2 or mTet3 with pNHP, pHEF-VSVG and pCEP4-Tat in 293FT cells. Viruses were collected from 16 to $60 \mathrm{~h}$ after transfection and titred for p24 levels using an ELISA kit (ZeptoMetrix Corporation, Buffalo, $\mathrm{NY}$ ). After the fibroblasts were thawed and passaged once more, they were plated at $5 \times 10^{3} \mathrm{~cm}^{-2}$ and infected 1 day later for $16 \mathrm{~h}$ with the indicated combinations of lentiviruses (hASCL1, hNurrl, hLmxla, hmiR-124 or hp53shRNA each at MOI 10, M2rtTA at MOI 20) in the presence of $8 \mu \mathrm{g} \mathrm{ml}^{-1}$ polybrene. Virus-containing media was removed after $16 \mathrm{~h}$ and replaced with DMEM containing 10\% FBS (which was omitted in experiments with cell cycle arrest), $2 \mathrm{mM}$ L-glutamine and doxycycline $\left(1 \mu \mathrm{g} \mathrm{ml}^{-1}\right)$. After $24 \mathrm{~h}$, the media was changed to neural induction media $\left(D M E M / F 12,1 \times \mathrm{N} 2\right.$ supplements, $1 \times \mathrm{NEAA}, 1 \times \mathrm{B} 27,20 \mathrm{ng} \mathrm{ml}^{-1}$ bFGF or NGF, $1 \mu \mathrm{M}$ dorsomorphin, $10 \mu \mathrm{M}$ SB431542, $3 \mu \mathrm{M}$ CHIR99021, $2 \mu \mathrm{M}$ purmorphamine, $0.2 \mathrm{mM}$ vitamin $\mathrm{C}, 10 \mu \mathrm{M}$ ROCK inhibitor Y27632, $20 \mathrm{ng} \mathrm{ml}^{-1}$ GDNF, $20 \mathrm{ng} \mathrm{ml}^{-1}$ BDNF and $1 \mathrm{ng} \mathrm{ml}^{-1}$ TGFß3) containing $1 \mu \mathrm{g} \mathrm{ml}^{-1}$ doxycycline. The media was changed every other day for the duration of the culture period. After 6 days' induction, dorsomorphin, SB431542, CHIR99021, purmorphamine and Dox were removed. In some experiments, we used full media, which is neural induction media minus bFGF and plus NGF $\left(20 \mathrm{ng} \mathrm{ml}^{-1}\right)$. Most experiments were completed at day 10. For experiments that went beyond 10 days, all media additives except GDNF, BDNF and TGF $\beta 3$ were removed from the full media from day 11 onward. In some experiments, basal media (DMEM/F12, $1 \times \mathrm{N} 2$ supplements, $1 \times \mathrm{NEAA}$ and $1 \times$ B27) was used instead.

Cell cycle analysis. Cell cycle profiles were analysed by the standard propidium iodide staining protocol. Briefly, cells were collected by trypsinization at indicated time points, fixed with cold $70 \%$ ethanol at $-20^{\circ} \mathrm{C}$ for at least $2 \mathrm{~h}$ and stained in propidium iodide master mix $\left(40 \mu \mathrm{g} \mathrm{ml}^{-1}\right.$ propidium iodide, $100 \mu \mathrm{g} \mathrm{ml}^{-1}$ DNase-free RNase and $0.1 \%(\mathrm{v} / \mathrm{v})$ Triton X-100) at $37^{\circ} \mathrm{C}$ for 30 min before analysis by flow cytometry. A minimum of 10,000 cells in each sample was sorted on a Becton-Dickinson FACS Caliber flow cytometer (San Jose, CA). Cell cycle was analysed using the CellQuest software (Becton-Dickinson) and plotted using FCS Express 4 software.

EdU incorporation assay. EdU labelling was performed using a kit from Invitrogen. Briefly, fibroblasts were incubated in media containing $10 \mu \mathrm{M}$ EdU at the specified time (0,24 or $48 \mathrm{~h}$ after Dox induction) for $2 \mathrm{~h}$. EdU pulse labelling for 2 or $24 \mathrm{~h}$ achieved the same effect, as the compound cannot diffuse out of the cells readily once it is taken up through selective transporters. After the cells were washed with regular media three times, they were cultured for another $24 \mathrm{~h}$ or 9 days before they were fixed in $4 \%$ paraformaldehyde, permeabilized with $0.1 \%$ Triton X-100 for 20 min at room temperature and stained in the detection cocktail ( $4 \mathrm{mM}$ copper sulfate, $40 \mathrm{mM}$ sodium ascorbate and $20 \mu \mathrm{M}$ Alexa Fluor 488 azide, $20 \mathrm{mM}$ Tris, $\mathrm{pH}=7.6$ ). Cells were counterstained with DAPI to identify nuclei.

Array comparative genomic hybridization analysis. Genomic DNA was extracted from MRC5 fibroblasts or iDA neurons at day 12 using QIAamp DNA Mini Kit (Qiagen). Array comparative genomic hybridization of the two samples was performed by the Genomics Shared Resource at Roswell Park Cancer Institute using Agilent Human Genome CGH Microarray 244A and scanned on Agilent Technologies Scanner G2505C. There are 236,381 oligonucleotide probes that are 60 nucleotides in length. The overall median probe spacing is $8.9 \mathrm{~kb}(7.4 \mathrm{~kb}$ median spacing in Refseq genes).

Dopamine release. DA release was measured as previously described ${ }^{25}$. Briefly, iDA neurons cultured in six-well plates were incubated at $37^{\circ} \mathrm{C}$ in $1 \mathrm{ml}$ HBSS for $30 \mathrm{~min}$ or in $1 \mathrm{ml} \mathrm{HBSS}$ for $15 \mathrm{~min}$ and then $56 \mathrm{mM} \mathrm{KCl}$ was added for another $15 \mathrm{~min}$, or in $1 \mathrm{ml} \mathrm{HBSS}$ without $\mathrm{Ca}^{2+}$ and without $\mathrm{Mg}^{2+}$, but with $2 \mathrm{mM}$ EDTA for $15 \mathrm{~min}$ and then $56 \mathrm{mM} \mathrm{KCl}$ was added for another $15 \mathrm{~min}$. The 1-ml HBSS solutions were taken out from the wells. The amounts of DA in HBSS solutions were measured by reverse phase HPLC (ESA Model 582 with ESA MD150 $\times 3.2$ column, at $0.6 \mathrm{ml} \mathrm{min}^{-1}$ flow rate in MD-TM mobile phase) coupled with electrochemical detection (ESA Coulochem III, E1: $-150 \mathrm{mV}, 2 \mu \mathrm{A}$; E2: $220 \mathrm{mV}$,
$2 \mu \mathrm{A})$. Cells in the wells were lysed in $0.5 \mathrm{~N} \mathrm{NaOH}$ to measure protein levels, which were used to normalize dopamine release.

Dopamine uptake. DA uptake was measured as previously described ${ }^{25}$. Briefly, iDA neurons cultured in six-well plates were rinsed with $1 \mathrm{ml}$ prewarmed uptake buffer (10 mM HEPES, $130 \mathrm{mM} \mathrm{NaCl}, 1.3 \mathrm{mM} \mathrm{KCl}, 2.2 \mathrm{mM} \mathrm{CaCl}, 1.2 \mathrm{mM}$ $\mathrm{MgSO}_{4}, 1.2 \mathrm{mM} \mathrm{KH} \mathrm{PO}_{4}, 10 \mathrm{mM}$ glucose, $\mathrm{pH}$ 7.4) three times. Cells were incubated for $5 \mathrm{~min}$ at $37^{\circ} \mathrm{C}$ with $1 \mathrm{ml}$ uptake buffer containing $5 \mu \mathrm{M}$ dopamine without or with $10 \mu \mathrm{M}$ nomifensine or $10 \mu \mathrm{M}$ GBR12909 (both are selective inhibitors of dopamine transporter). After the cells were washed at least three times in uptake buffer, they were lysed in $0.1 \mathrm{M}$ perchloric acid with $1 \mathrm{mM}$ EDTA and $0.1 \mathrm{mM}$ sodium bisulfite. Cleared cell lysates were analysed for dopamine on HPLC coupled with electrochemical detection (E1: $-150 \mathrm{mV}, 2 \mu \mathrm{A}$; E2: $220 \mathrm{mV}, 2 \mu \mathrm{A}$ ). The pellets of cellular proteins were dissolved in $1 \mathrm{ml} 0.5 \mathrm{~N} \mathrm{NaOH}$ to measure protein contents, which were used to normalize dopamine uptake. The amount of endogenous dopamine in $\mathrm{DDA}$ neurons without any treatment was also measured.

Immunocytochemistry and morphological analysis of neurites. Cells grown in 12-well plates were fixed in situ with $4 \%$ paraformaldehyde in PBS for $20 \mathrm{~min}$, permeabilized with $0.1 \%$ Triton X-100 in PBS for $15 \mathrm{~min}$ at room temperature, blocked in 3\% BSA in PBS for $60 \mathrm{~min}$ at room temperature and then incubated in primary antibody overnight at $4^{\circ} \mathrm{C}$, secondary antibody for $2 \mathrm{~h}$ at room temperature. The sources, catalogue numbers and dilutions of the antibodies used in this study are listed in Supplementary Table 2. Fluorescence images were taken on Zeiss Axio Observer Inverted Microscope with lenses corrected for plastic culture plates. $\mathrm{TH}^{+}, \mathrm{Tuj}^{+}{ }^{+}$and DAPI ${ }^{+}$cells were counted blindly by a different person from 10 randomly selected images at $\times 10$ magnification for each condition. In all, 30-60 $\mathrm{TH}^{+}$neurons from three independent experiments for each condition were traced and analysed blindly for total neurite length using NIH ImageJ with the NeuronJ plugin ${ }^{26}$. The number of neurites was counted manually after tracing. To avoid any ambiguity, neurons with overlapping neurites were excluded from analysis.

Real time quantitative RT-PCR. Total RNA was extracted using RNeasy Mini kit (Qiagen). Further DNA removal was performed with the RNase-Free DNase Set (Qiagen). First-strand cDNA was synthesized with oligo dT or random hexamers as primers, using SuperScript First-Strand Synthesis System according to the manufacturer's protocol (Life Technologies). An equal volume mixture of the products was used as templates for PCR amplification. Reactions were performed in a $25-\mu \mathrm{l}$ volume with iQ SYBR Green Supermix (Bio-Rad) and $200 \mathrm{nM}$ each of forward and reverse primers shown in Supplementary Table 3 using iCyler and iQ software (Bio-Rad). Each sample was run in triplicate. PCR conditions included an initial denaturation step of 4 min at $95^{\circ} \mathrm{C}$, followed by 40 cycles of PCR consisting of $30 \mathrm{~s}$ at $95^{\circ} \mathrm{C}, 30 \mathrm{~s}$ at $60^{\circ} \mathrm{C}$ and $30 \mathrm{~s}$ at $72^{\circ} \mathrm{C}$. Average threshold cycle $(\mathrm{Ct})$ values from the triplicate PCR reactions for a gene of interest were normalized against the average $\mathrm{Ct}$ values for GAPDH from the same cDNA sample.

5hmC dot blot. Genomic DNA was extracted with QIAamp DNA mini kit (Qiagen). A unit of 200 or $500 \mathrm{ng}$ genomic DNA was denatured in $0.1 \mathrm{M} \mathrm{NaOH}$ at $100^{\circ} \mathrm{C}$ for $10 \mathrm{~min}$ and followed by the addition of an equal volume of cold $2 \mathrm{M}$ ammonium acetate ( $\mathrm{pH}$ 7.2). Denatured DNA samples were spotted on a nitrocellulose membrane and crosslinked by ultraviolet with Stratalinker 2400 twice. The membrane was blocked with $5 \%$ non-fat milk for $1 \mathrm{~h}$ and incubated with anti-5hmC for detection by ECL.

Electrophysiology. Recordings of spontaneous EPSC (sEPSC) used standard whole-cell voltage-clamp techniques ${ }^{25,52}$. The membrane potential was held at $-70 \mathrm{mV}$. The external solution contained (in $\mathrm{mM}$ ): $130 \mathrm{NaCl}, 26 \mathrm{NaHCO}_{3}, 3 \mathrm{KCl}$, $5 \mathrm{MgCl}_{2}, 1 \mathrm{CaCl}_{2}, 1.25 \mathrm{NaH}_{2} \mathrm{PO}_{4}$ and 10 glucose, $\mathrm{pH}$ 7.3-7.4, 300-305 mOsm. To isolate AMPAR-mediated response, the NMDA receptor antagonist D-aminophosphonovalerate $(50 \mu \mathrm{M})$ and $\mathrm{GABA}_{\mathrm{A}}$ receptor antagonist bicuculline $(10 \mu \mathrm{M})$ were added. The internal solution consisted of the following (in $\mathrm{mM}): 130$ Cs methanesulfonate, $10 \mathrm{CsCl}, 4 \mathrm{NaCl}, 10 \mathrm{HEPES}, 1 \mathrm{MgCl}_{2}, 5$ EGTA, 2.2 QX-314, 12 phosphocreatine, $5 \mathrm{MgATP}, 0.2 \mathrm{Na}_{2} \mathrm{GTP}$ and 0.1 leupeptin, $\mathrm{pH}$ 7.2-7.3, 265-270 mOsm. For the recording of action potentials, whole-cell current-clamp recordings were performed with the internal solution containing (in $\mathrm{mM}$ ): 125 K-gluconate, $10 \mathrm{KCl}, 10 \mathrm{HEPES}, 0.5 \mathrm{EGTA}, 3 \mathrm{Na}_{2} \mathrm{ATP}, 0.5 \mathrm{Na}_{2} \mathrm{GTP}$ and 12 phosphocreatine, $\mathrm{pH} 7.25,280 \mathrm{mOsm}$. Cells were perfused with ACSF, and membrane potentials were kept at -55 to $-65 \mathrm{mV}$. A series of hyperpolarizing and depolarizing step currents were injected to measure intrinsic properties and to elicit action potentials. Spontaneous action potentials were recorded without current injection. For the recording of voltage-dependent sodium and potassium currents, cells (held at $-70 \mathrm{mV}$ ) were perfused with artificial cerebrospinal fluid (ACSF), and voltage steps ranging from -90 to $+50 \mathrm{mV}$ were delivered at $10-\mathrm{mV}$ increments. Data analyses were performed with Clampfit (Axon instruments) and Kaleidagraph (Albeck Software). 
Statistical analyses. All statistical analyses were done with the software Origin (OriginLab, Northampton, MA). The data were expressed as mean \pm s.e.m. (standard error of measurement). Unpaired, two-tailed Student's $t$-tests were performed to evaluate whether two groups were significantly different from each other. Sample size is chosen based on previous studies in the field with similar measurements. No sample is excluded in our analysis.

\section{References}

1. Davis, R. L., Weintraub, H. \& Lassar, A. B. Expression of a single transfected cDNA converts fibroblasts to myoblasts. Cell 51, 987-1000 (1987).

2. Yamanaka, S. Induced pluripotent stem cells: past, present, and future. Cell Stem Cell 10, 678-684 (2012).

3. Hanna, J. et al. Direct cell reprogramming is a stochastic process amenable to acceleration. Nature 462, 595-601 (2009).

4. Zhao, Y. et al. Two supporting factors greatly improve the efficiency of human iPSC generation. Cell Stem Cell 3, 475-479 (2008).

5. Kawamura, T. et al. Linking the p53 tumour suppressor pathway to somatic cell reprogramming. Nature 460, 1140-1144 (2009).

6. Li, H. et al. The Ink4/Arf locus is a barrier for iPS cell reprogramming. Nature 460, 1136-1139 (2009).

7. Marion, R. M. et al. A p53-mediated DNA damage response limits reprogramming to ensure iPS cell genomic integrity. Nature 460, 1149-1153 (2009)

8. Utikal, J. et al. Immortalization eliminates a roadblock during cellular reprogramming into iPS cells. Nature 460, 1145-1148 (2009).

9. Hong, H. et al. Suppression of induced pluripotent stem cell generation by the p53-p21 pathway. Nature 460, 1132-1135 (2009).

10. Caiazzo, M. et al. Direct generation of functional dopaminergic neurons from mouse and human fibroblasts. Nature 476, 224-227 (2011).

11. Pfisterer, U. et al. Direct conversion of human fibroblasts to dopaminergic neurons. Proc. Natl Acad. Sci. USA 108, 10343-10348 (2011).

12. Kim, J. et al. Functional integration of dopaminergic neurons directly converted from mouse fibroblasts. Cell Stem Cell 9, 413-419 (2011).

13. Vierbuchen, T. et al. Direct conversion of fibroblasts to functional neurons by defined factors. Nature 463, 1035-1041 (2010).

14. Ieda, M. et al. Direct reprogramming of fibroblasts into functional cardiomyocytes by defined factors. Cell 142, 375-386 (2010).

15. Sekiya, S. \& Suzuki, A. Direct conversion of mouse fibroblasts to hepatocytelike cells by defined factors. Nature 475, 390-393 (2011).

16. Szabo, E. et al. Direct conversion of human fibroblasts to multilineage blood progenitors. Nature 468, 521-526 (2010).

17. Vierbuchen, T. \& Wernig, M. Molecular roadblocks for cellular reprogramming. Mol. Cell 47, 827-838 (2012).

18. Farah, M. H. et al. Generation of neurons by transient expression of neural bHLH proteins in mammalian cells. Development 127, 693-702 (2000).

19. Wu, H. \& Zhang, Y. Mechanisms and functions of Tet protein-mediated 5-methylcytosine oxidation. Genes Dev. 25, 2436-2452 (2011).

20. Kriaucionis, S. \& Heintz, N. The nuclear DNA base 5-hydroxymethylcytosine is present in Purkinje neurons and the brain. Science 324, 929-930 (2009).

21. Gao, Y. et al. Replacement of Oct4 by Tet1 during iPSC induction reveals an important role of DNA methylation and hydroxymethylation in reprogramming. Cell Stem Cell 12, 453-469 (2013).

22. Park, I. H. et al. Reprogramming of human somatic cells to pluripotency with defined factors. Nature 451, 141-146 (2008).

23. Yoo, A. S. et al. MicroRNA-mediated conversion of human fibroblasts to neurons. Nature 476, 228-231 (2011).

24. Ambasudhan, R. et al. Direct reprogramming of adult human fibroblasts to functional neurons under defined conditions. Cell Stem Cell 9, 113-118 (2011).

25. Jiang, H. et al. Parkin controls dopamine utilization in human midbrain dopaminergic neurons derived from induced pluripotent stem cells. Nat. Commun. 3, 668 (2012).

26. Meijering, E. et al. Design and validation of a tool for neurite tracing and analysis in fluorescence microscopy images. Cytometry A 58, 167-176 (2004).

27. Vassilev, L. T. et al. In vivo activation of the $\mathrm{p} 53$ pathway by small-molecule antagonists of MDM2. Science 303, 844-848 (2004).

28. Momand, J., Zambetti, G. P., Olson, D. C., George, D. \& Levine, A. J. The mdm-2 oncogene product forms a complex with the p53 protein and inhibits p53-mediated transactivation. Cell 69, 1237-1245 (1992).

29. Levine, A. J. \& Oren, M. The first 30 years of p53: growing ever more complex. Nat. Rev. Cancer 9, 749-758 (2009).

30. Jarviluoma, A. et al. Phosphorylation of the cyclin-dependent kinase inhibitor p21Cip1 on serine 130 is essential for viral cyclin-mediated bypass of a p21Cip1-imposed G1 arrest. Mol. Cell Biol. 26, 2430-2440 (2006).
31. Lane, M. E. et al. A novel cdk2-selective inhibitor, SU9516, induces apoptosis in colon carcinoma cells. Cancer Res. 61, 6170-6177 (2001).

32. Thoreen, C. C. et al. An ATP-competitive mammalian target of rapamycin inhibitor reveals rapamycin-resistant functions of mTORC1. J. Biol. Chem. 284 8023-8032 (2009).

33. Dowling, R. J. et al. mTORC1-mediated cell proliferation, but not cell growth, controlled by the 4E-BPs. Science 328, 1172-1176 (2010).

34. Coller, H. A., Sang, L. \& Roberts, J. M. A new description of cellular quiescence. PLoS Biol. 4, e83 (2006).

35. Sang, L., Coller, H. A. \& Roberts, J. M. Control of the reversibility of cellular quiescence by the transcriptional repressor HES1. Science 321, 1095-1100 (2008).

36. Watanabe, K. et al. A ROCK inhibitor permits survival of dissociated human embryonic stem cells. Nat. Biotechnol. 25, 681-686 (2007).

37. Li, W. et al. Rapid induction and long-term self-renewal of primitive neural precursors from human embryonic stem cells by small molecule inhibitors. Proc. Natl Acad. Sci. USA 108, 8299-8304 (2011).

38. Esteban, M. A. et al. Vitamin C enhances the generation of mouse and human induced pluripotent stem cells. Cell Stem Cell 6, 71-79 (2010).

39. Kim, D. S. et al. Robust enhancement of neural differentiation from human ES and iPS cells regardless of their innate difference in differentiation propensity. Stem Cell Rev. 6, 270-281 (2010).

40. Chambers, S. M. et al. Highly efficient neural conversion of human ES and iPS cells by dual inhibition of SMAD signaling. Nat. Biotechnol. 27, 275-280 (2009).

41. Stacpoole, S. R. et al. Efficient derivation of NPCs, spinal motor neurons and midbrain dopaminergic neurons from hESCs at $3 \%$ oxygen. Nat. Protoc. 6, 1229-1240 (2011).

42. Yang, Y. C. et al. Hierarchical model of gene regulation by transforming growth factor beta. Proc. Natl Acad. Sci. USA 100, 10269-10274 (2003).

43. Roussa, E. et al. Transforming growth factor beta is required for differentiation of mouse mesencephalic progenitors into dopaminergic neurons in vitro and in vivo: ectopic induction in dorsal mesencephalon. Stem Cells 24, 2120-2129 (2006).

44. Cai, J. et al. BMP and TGF-beta pathway mediators are critical upstream regulators of Wnt signaling during midbrain dopamine differentiation in human pluripotent stem cells. Dev. Biol. 376, 62-73 (2013).

45. Derynck, R. \& Zhang, Y. E. Smad-dependent and Smad-independent pathways in TGF-beta family signalling. Nature 425, 577-584 (2003).

46. Inman, G. J. et al. SB-431542 is a potent and specific inhibitor of transforming growth factor-beta superfamily type I activin receptor-like kinase (ALK) receptors ALK4, ALK5, and ALK7. Mol. Pharmacol. 62, 65-74 (2002).

47. Wang, Y. \& Zhang, Y. Regulation of TET protein stability by calpains. Cell Rep. 6, 278-284 (2014)

48. Arioka, Y., Watanabe, A., Saito, K. \& Yamada, Y. Activation-induced cytidine deaminase alters the subcellular localization of Tet family proteins. PLoS ONE 7, e45031 (2012)

49. L'hirondel, M. et al. Lack of autoreceptor-mediated inhibitory control of dopamine release in striatal synaptosomes of D2 receptor-deficient mice. Brain Res. 792, 253-262 (1998).

50. Hsu, C. H. et al. TET1 suppresses cancer invasion by activating the tissue inhibitors of metalloproteinases. Cell Rep. 2, 568-579 (2012).

51. Deplus, R. et al. TET2 and TET3 regulate GlcNAcylation and H3K4 methylation through OGT and SET1/COMPASS. EMBO J. 32, 645-655 (2013)

52. Yuen, E. Y. et al. Mechanisms for acute stress-induced enhancement of glutamatergic transmission and working memory. Mol. Psychiatry 16, 156-170 (2011).

\section{Acknowledgements}

The work was supported by the Department of Veterans Affairs Merit Award I01BX002452; National Key Basic Research Program of China grants 2011CB504100 and 2010CB945200; NYSTEM contracts C028129, C029556 and C026714; NIH grant NS061856; and SUNY REACH. We thank Dr Wade J. Sigurdson, Director of Confocal Microscope and Flow Cytometry Facility at SUNY Buffalo for help with confocal microscopy and Dr Xinjiang Wang at Roswell Park Cancer Institute for providing the CDNA for human MDM2.

\section{Author contributions}

J.F. designed the research and wrote the manuscript with H.J., X.W., S.C. and Z.Y.; H.J. generated the iDA neurons and performed most the analyses; Z.X., Y.R., H.A.S. and Z.H. quantified and analysed the iDA neurons; G.L. and Y.Z. generated the lentiviral expression constructs for mouse Tet1, Tet2 and Tet3; P.Z. performed electrophysiological studies, which were designed and analysed by Z.Y. 


\section{Additional information}

Accession codes: The array comparative genomic hybridization data have been deposited in the GEO database under accession code GSE52352.

Supplementary Information accompanies this paper at http://www.nature.com/ naturecommunications

Competing financial interests: The authors declare no competing financial interests.

Reprints and permission information is available online at http://npg.nature.com/ reprintsandpermissions/
How to cite this article: Jiang, H. et al. Cell cycle and p53 gate the direct conversion of human fibroblasts to dopaminergic neurons. Nat. Commun. 6:10100 doi: $10.1038 /$ ncomms10100 (2015)

cc (i) This work is licensed under a Creative Commons Attribution 4.0 International License. The images or other third party material in this article are included in the article's Creative Commons license, unless indicated otherwise in the credit line; if the material is not included under the Creative Commons license, users will need to obtain permission from the license holder to reproduce the material. To view a copy of this license, visit http://creativecommons.org/licenses/by/4.0/ 